\title{
Dissecting the yield curve: The international evidence
}

\author{
Andrea Berardi and Alberto Plazz**
}

\begin{abstract}
We develop a term structure model that decomposes nominal yields into the sum of an expectation, term premium, and convexity term and in turn of their real and inflation counterparts. The model explicitly captures the interrelation between yield-only and macroeconomic factors while allowing for aggregate stochastic volatility. We extract the components from the nominal and real yield curve of the United States, the Euro Area, the United Kingdom, and Japan. We find that short-rate expectations have steadily declined over the last two decades and account for the bulk of yield dynamics. Term premia increase with maturity but explain a smaller fraction of yield forecast error variance than previously documented. With regard to yield comovement, the United States generates the strongest spillovers at the long end of the yield curve, whereas the Japanese market is the top importer of shocks.
\end{abstract}

Keywords: Term structure, term premium, yield volatility, macro factors, comovement

JEL classification: G12, E43, E44, C58

\footnotetext{
*Berardi is with the Department of Economics, Università Ca' Foscari Venezia, Fondamenta San Giobbe 873, 30121, Venezia, Italy, Email: andrea.berardi@unive.it. Plazzi is with the Institute of Finance, Università della Svizzera italiana and Swiss Finance Institute, Via Buffi 13, 6900, Lugano, Switzerland, E-mail: alberto.plazzi@usi.ch. We thank Geert Bekaert (Editor) and three anonymous referees for their remarks and comments that considerably improved the paper. We also thank Alexander Bechtel, Massimilano Caporin, Iryna Kaminska, Jean-Paul Renne, Stephen Schaefer, and seminar participants at the CFECMStatistics 2018 Conference and Paris December 2019 Finance Meeting for comments. Berardi gratefully acknowledges financial support from the European Union's Horizon 2020 research and innovation programme under the Marie SklodowskaCurie grant agreement No 793763. Part of this project was conducted while Berardi was Fellow at Long-TermInvestors@UniTo, whose research support is gratefully appreciated.
} 


\section{Introduction}

The last two decades have been characterized by pronounced variation in nominal interest rates across maturities and countries, as well as over time (see, for example, Hördahl et al., 2016; Mönch, 2019). Fluctuations in the term structure of yields originate from changes in expectations and risk compensation of either their inflation side, their real side, or both. Disentangling the relative contribution of these effects is relevant for the transmission of monetary policy and for investors' and firms' saving and investment decisions.

In this paper, we develop a no-arbitrage term structure model that features both macroeconomic and volatility factors while still allowing for affine closed-form expressions for real and nominal yields. ${ }^{1}$ Through the model, we decompose nominal yields into investors' expectations of future short rates over the bond maturity and a term premium component, which represents the compensation for holding a long-term bond relative to a series of short-term bonds and thus depends on interest rate uncertainty. We then split the first component into the sum of expected inflation and the expected real rate over the term of the bond. The nominal term premium can also be expressed as the sum of a real term premium and an inflation term premium, which captures the compensation for bearing the risk of unanticipated changes in future inflation perceived by investors holding nominal bonds. Moreover, we separately identify an additional (time-varying) convexity term that is typically lumped into the term premium in Gaussian models (Kim and Wright, 2005; Adrian et al., 2013).

Our modelling framework consists of five latent state variables. We express the instantaneous real interest rate as an affine function of two variables, which represent its "slope" and "level," in the spirit of Abrahams et al. (2016). We include two latent factors capturing market expectations about future inflation and real growth and thus time variation in the economic outlook. A number of studies show that macroeconomic data, in the form of either macro indicators or forward-looking survey expectations thereof, contain information about bond risk premia that is missed by yields. ${ }^{2}$ Finally, we account for stochastic volatility

\footnotetext{
${ }^{1}$ See Joyce et al. (2010), Haubrich et al. (2012), Abrahams et al. (2016), Kaminska et al. (2018), and D'Amico et al. (2018) for studies that use affine models to jointly study real and nominal yield curves.

${ }^{2}$ For the use of macro indicators, see Ludvigson and Ng (2009), Bikbov and Chernov (2010), Joslin et al. (2014), and Kopp
} 
through a factor that enters risk premia and the conditional volatility of all other factors. Among others, Cieslak and Povala (2016), Feldhütter et al. (2018), and Berardi et al. (2021) emphasize the role of stochastic volatility for time-varying risk premia. ${ }^{3}$

We use the model to study the yield curve of four currency areas - the US, the Euro Area, the UK, and Japan - over the January 1999 to December 2018 period. We estimate the model with a Kalman filter algorithm using data on the following: nominal yields as proxied by interest rate swap rates; breakeven (i.e., inflation) swap rates; surveys of professional forecasts for consumer price index (CPI) changes and real gross domestic product (GDP) growth rates; and realized and swaption-implied nominal yield variances. This rich information structure allows us to exploit the model cross-sectional restrictions efficiently.

The estimates reveal a few important regularities across countries. Short-rate expectations under the physical measure are, on average, by far the largest component of nominal yields. Over time, they display a sustained decline, with a rebound in recent years for the US and the UK. This pattern is largely due to a downward trend in real rate expectations in the four markets since 2001, whereas inflation expectations have remained stable or displayed a slight decrease for the US and Euro Area. We also observe a decline in the countries' model-implied long-run "equilibrium" real interest rate, computed as the average expected real short rate over a five-year period starting five years ahead (see Christensen and Rudebusch, 2019). This long-run rate has recovered in recent years and reached 100 basis points (bps) at the end of the sample for all countries but the UK, where it has remained negative since 2015 .

For the US, the Euro Area, and the UK, nominal term premia are on average positive and increase with maturity. They are around 100 bps in the early part of the sample and during the global financial crisis and have decreased since then toward zero and below, with much of the effect coming from the real side. The average 10-year inflation term premium is about 15 bps for the Euro Area and 30 bps for the US and the UK. For Japan, by contrast, both

and Williams (2018) for the US and Hördahl and Tristani (2012) and Garcia and Werner (2016) for the Euro Area. For the use of either macro or yield survey data, see Chun (2010), Kim and Wright (2005), Kim and Orphanides (2012), Crump et al. (2018), and Kaminska et al. (2018).

${ }^{3}$ For the US, Adrian and Wu (2009), Haubrich et al. (2012), and Berardi and Plazzi (2019) document the existence of a positive relation between volatility and inflation risk premia. 
the average inflation and real term premia are negative, and increasingly so with maturity. Finally, we detect economically relevant convexity effects that spike during turbulent periods and persist thereafter, mostly coming from the real side. For example, during the financial crisis, the US convexity effect is about the same size as the term premium.

When decomposing yield forecast error variance using the Diebold and Yilmaz (2012) framework, we find that short-rate expectations account for the largest fraction (more than $90 \%)$ at the short end. This figure decreases as maturity lengthens but remains as high as two-thirds for 10-year nominal yields in the US, the Euro Area, and the UK. Only in the case of Japan do we observe an equal contribution of short-rate expectations and term premium at the long end. If we further split the components into their inflation and real counterparts, it emerges that the real side drives most of the yield forecast error variance, explaining about $80 \%$ of it at the 10-year maturity, consistent with Bekaert and Ermolov (2021).

The finding that short-rate expectations are the driving force behind nominal yield fluctuations is in contradiction with evidence from Wright (2011), Jotikasthira et al. (2015), and Mönch (2019). To identify the reason for this difference, we run a number of analyses. First, we make sure our conclusions are not due to obvious model misspecifications. We verify that the model delivers economically modest fitting errors and reasonable model-implied maximal Sharpe Ratios (Duffee, 2010). The model also matches the degree of deviation from the Expectations Hypothesis that is found in the data using Campbell and Shiller's (1991) regressions. Moreover, when relying on the specification that uses long-term changes in short rates as the dependent variable, we find that the extent of rejection is not as severe for some countries and maturities, which suggests a stronger role for the expectations component.

Second, we estimate Wright's (2011) Gaussian five-factor affine model on our sample period and dataset. We confirm his conclusion that the term premium implied by this framework accounts for most of the 10-year nominal yield forecast error variance. Hence, our result is not driven by the specific input series we use or by a change in the data-generating process throughout the sample.

Third, we estimate three competing affine models: the five-factor homoskedastic model 
of Adrian et al. (2013), which does not include stochastic volatility and macro factors; a homoskedastic four-factor model with macro factors but without stochastic volatility; and a stochastic volatility four-factor model without output growth. We find that simultaneously anchoring the estimation to macroeconomic information while accounting for time-varying volatility reduces the variability in the resulting nominal term premium and shifts the lion's share of yield fluctuations toward short-rate expectations.

Our results are derived in an affine setting. However, many authors have stressed the importance of nonlinearities. ${ }^{4}$ Particularly close to the scope of our paper is Ang et al. (2008), who identify the role of the real and inflation components of the yield curve within a regime-switching model where the inflation and latent term structure factor feature statedependent conditional mean and volatility. ${ }^{5}$ In an effort to measure how our conclusions are shared by a model that directly accounts for nonlinearities, we compare our nominal term premia to those from a four-factor version of the nonlinear model of Feldhütter et al. (2018). We find that while the two series average about the same, the term premia from Feldhütter et al.'s (2018) model are more volatile and account for most of yield forecast error variance. Their model fits observed yields well, yet it struggles to fit yield variances accurately. This evidence suggests that the two approaches are not close substitutes and that our stochastic volatility framework may be more suitable to study yield dynamics, at least during the sample period we consider.

Lastly, we examine yield comovements in the cross section of markets. A few studies document the presence of common global factors and spillovers among bond markets of the major industrialized countries (see, e.g., Barr and Priestley, 2004; Dahlquist and Hasseltoft, 2013; Jotikasthira et al., 2015). We show that our model is able to match the extent of observed international yield correlations. Since model-implied yields are linear combinations of the latent state variables, international yield comovements depend on the correlation

\footnotetext{
${ }^{4}$ Notable approaches in this direction include quadratic models (Ahn et al., 2002; Leippold and Wu, 2002; Chen et al., 2010) and regime switches (Clarida et al., 2006; Bansal et al., 2004; Dai et al., 2007; Ang et al., 2008; Chib and Kang, 2012; Bikbov and Chernov, 2013).

${ }^{5}$ Unlike Ang et al. (2008), we make explicit use of inflation swap rate data, which allow us to capture the average level of real rates without imposing restrictions on the one-period inflation risk premium. This, however, comes at the cost of a much shorter time span, which limits our ability to pin down nonlinear effects. Despite these differences, we also find evidence of an inflation risk premium that increases with maturity as in Ang et al. (2008).
} 
structure of the countries' state vectors and on the country-specific loadings. We thus resort to the Diebold and Yilmaz (2012) decomposition to identify the relative importance of ownand cross-country components in driving yield forecast error variance. We find that some foreign yield components play an economically significant role in explaining country yield variation. This leads to a relatively large total spillover index, most of which originates from the real side, a finding that resonates with the results in Bekaert and Ermolov (2021). Looking at net spillovers, the US is the strongest exporter of shocks to the long end of the nominal yield curve, consistent with the literature that posits the role of US shocks as leading indicators in international markets (see, e.g., Rapach et al., 2013; Brusa et al., 2020; Caporin et al., 2020). The UK is also a mildly positive net transmitter of shocks, while the Japanese market is the top recipient.

The rest of the paper is structured as follows. Section 2 outlines the term structure model and works out the yield decomposition. Section 3 describes the data. Section 4 presents model diagnostics and our main empirical results on yield components, and Section 5 reports the analysis of cross-country comovement. Finally, section 6 offers concluding remarks.

\section{The model}

In this section, we outline our term structure model. The framework falls in the class of affine models that simultaneously deliver closed-form expressions for the term structure of both nominal and real yields (see, inter alia, Abrahams et al., 2016; Kaminska et al., 2018). Section 2.1 describes the data-generating process and the specification of risk premia. Section 2.2 presents the implied no-arbitrage term structure for nominal and real rates and decomposes the resulting term structure of nominal yields.

\subsection{State variables and the macroeconomy}

We posit that the economy is driven by five latent factors that are collected in the state vector $X=(v \mu \pi s \ell)^{\prime}$. The variance factor, $v$, is meant to capture aggregate uncertainty 
and is responsible for time variation in the conditional volatility of all the other variables. The instantaneous conditional mean of output growth, $\mu$, and of the inflation rate, $\pi$, capture investors' expectations of real growth and nominal price growth, respectively. Finally, we express the instantaneous real interest rate $r$ as the sum of two variables $s$ and $\ell$, or $r=$ $s+\ell$. This specification shares similarities with Abrahams et al. (2016), where the first two principal components of Treasury inflation protected securities (TIPS) yields are used to model the level and slope of real interest rates. As a preview, the Kalman filter estimates of the model reveal that $s$ is strongly correlated with the slope of the term structure of real interest rates, computed as the real short-term rate minus the real long-term rate, and $\ell$ with the long-term real interest rate. Therefore, we refer below to $s$ and $\ell$ as the "slope" and "level" factors of real rates, respectively.

Under the physical probability measure $\mathbb{P}$, we let the vector $X$ evolve according to the Ito process:

$$
d X_{t}=K\left(\Theta-X_{t}\right) d t+\Sigma \sqrt{S_{t}} d z_{t}
$$

where $z_{t}$ is a vector of independent Brownian motions, $K$ is a $(5 \times 5)$ matrix of mean-reversion coefficients, $\Theta$ is a $(5 \times 1)$ vector of long-term expectations, $\Sigma$ is a $(5 \times 5)$ lower triangular matrix obtained as $\Sigma=\left(\Xi \Omega \Xi^{\prime}\right)^{\frac{1}{2}}$, where $\Xi$ is a $(5 \times 5)$ diagonal matrix of volatility coefficients and $\Omega$ a $(5 \times 5)$ correlation matrix, and $S_{t}$ is diagonal $(5 \times 5)$, with the element in position $(i, i)$ given by $\left[S_{t}\right]_{i i}=\beta_{i}^{\prime} X_{t}$ and $\beta_{i}$ denoting the $i$-th column of the $(5 \times 5)$ matrix $\beta$, which has ones in the first row and zeros elsewhere.

To comply with Dai and Singleton's (2000) admissibility constraints, we impose that the off-diagonal terms of the first row of $K$ are null. This implies that the first factor $v$ follows a square root process that enters the diffusion term of the other four conditionally Gaussian factors. In addition, $v$ can provide information on the expected level of the other state variables through the first column of the mean-reversion matrix $K$. The four variables $\mu, \pi$, $s$, and $\ell$ potentially interact with each other through both the drift term and correlation in their innovations.

We characterize the dynamics under the risk-adjusted probability measure $\mathbb{Q}$ by using the 
"essentially affine" specification of the instantaneous market price of risk of Duffee (2002):

$$
\Psi_{t}=\sqrt{S_{t}^{-}}\left(\Lambda_{0}+\Lambda_{1} X_{t}\right)
$$

where $S_{t}^{-}$denotes the inverse of $S_{t}, \Lambda_{0}$ is a $(5 \times 1)$ vector of constant risk premia, and $\Lambda_{1}$ is $(5 \times 5)$. This specification allows risk premia to vary over time with $X_{t}$ and to potentially turn negative. Moreover, it implies that the dynamics of $X_{t}$ under $\mathbb{Q}$ are also affine, with the same diffusion term as in Eq. (1) and risk-adjusted $\operatorname{drift}\left(\widetilde{K} \widetilde{\Theta}-\widetilde{K} X_{t}\right)$ being $\widetilde{K}=K+\Sigma \Lambda_{1}$ and $\widetilde{K} \widetilde{\Theta}=K \Theta-\Sigma \Lambda_{0}$.

In order to enhance the identification of the latent macro factors, we explicitly link them to the realized process for price level and output growth, in the spirit of Ang and Piazzesi (2003), Wright (2011), and Joslin et al. (2014). We assume that the exogenously given equilibrium price level $p$ of the single physical good and its real production output $q$ follow Ito processes with time-varying drifts and volatilities:

$$
\begin{aligned}
\frac{d p_{t}}{p_{t}} & =\pi_{t} d t+\gamma_{p} d w_{p, t}+\sigma_{p} \sqrt{v_{t}} d u_{p, t} \\
\frac{d q_{t}}{q_{t}} & =\mu_{t} d t+\xi\left(\gamma_{q} d w_{p, t}+\sigma_{q} \sqrt{v_{t}} d u_{p, t}\right)+\sqrt{1-\xi^{2}}\left(\gamma_{q} d w_{q, t}+\sigma_{q} \sqrt{v_{t}} d u_{q, t}\right)
\end{aligned}
$$

with $w_{t}$ s and $u_{t}$ s being uncorrelated Brownian motions. The variables $\pi$ and $\mu$ therefore play the role of the conditional means of the inflation rate and real output growth, respectively. In addition, the stochastic volatility factor generates conditional heteroscedasticity in both processes and thus captures commonality in their volatility dynamics.

\subsection{Term structure and yield components}

Based on the assumptions above, the real stochastic discount factor (SDF) $M_{t}$ follows the process

$$
\frac{d M_{t}}{M_{t}}=-r_{t} d t-\Psi_{t}^{\prime} d z_{t}
$$


while Ito's lemma implies that the SDF that prices nominal assets $M_{t}^{\$}=M_{t} / p_{t}$ follows

$$
\frac{d M_{t}^{\$}}{M_{t}^{\$}}=\frac{d M_{t}}{M_{t}}-\frac{d p_{t}}{p_{t}}+\left(\frac{d p_{t}}{p_{t}}\right)^{2}-\frac{d M_{t}}{M_{t}} \frac{d p_{t}}{p_{t}} .
$$

By imposing the no-arbitrage condition that the drift of this process equals (minus) the equilibrium instantaneous nominal interest rate $y_{t}$, we obtain

$$
y_{t}=\pi_{t}+r_{t} \underbrace{-\frac{1}{d t} \operatorname{Var}_{t}\left(\frac{d p_{t}}{p_{t}}\right)+\frac{1}{d t} \operatorname{Cov}_{t}\left(\frac{d M_{t}}{M_{t}}, \frac{d p_{t}}{p_{t}}\right)}_{\text {irpt }},
$$

where $\operatorname{irp}_{t}$ denotes the instantaneous inflation risk premium. Combining Eq. (2), Eq. (3), Eq. (5), and Eq. (7), we can express $\operatorname{irp}_{t}$ as a linear function of the state vector $X_{t}$ :

$$
i r p_{t}=-\sigma_{p}^{2} v_{t}-\sigma_{p} \sqrt{v_{t}}\left(\Lambda_{0}+\Lambda_{1} X_{t}\right)^{\prime}\left(\sqrt{S_{t}^{-}}\right)^{\prime} \Gamma \equiv \varphi_{0}+\varphi^{\prime} X_{t}
$$

with $\Gamma=\operatorname{Corr}\left(d u_{p, t}, d z_{t}\right)$ being $(5 \times 1)$, which in turn entails that the instantaneous nominal interest rate $y_{t}$ is affine in $X_{t}$, or $y_{t}=\delta_{0}+\delta^{\prime} X_{t}$, with $\delta_{0}=\varphi_{0}$ and $\delta^{\prime}=\left(\begin{array}{llll}0 & 0 & 1 & 1\end{array}\right)+\varphi^{\prime}$. This result, together with the affine risk-neutral dynamics of the state vector, implies that the time- $t$ equilibrium arbitrage-free price of a nominal unit discount bond with time to maturity $\tau$ has an exponentially affine closed-form solution; namely,

$$
F_{t}(\tau)=\exp \left\{A(\tau)-B^{\prime}(\tau) X_{t}\right\}
$$

The nominal term structure is thus affine in the state vector:

$$
Y_{t}(\tau)=a(\tau)+b^{\prime}(\tau) X_{t}
$$

where $a(\tau) \equiv-A(\tau) / \tau$ and $b(\tau) \equiv B(\tau) / \tau$, and $A(\tau)$ and $B(\tau)$ solve the no-arbitrage system of ordinary differential equations (Piazzesi, 2010).

The expression in Eq. (10) relates yields to the state vector through a linear function whose coefficients embed both a risk-adjustment and the expectation of the future path of the 
short rate, plus a Jensen's inequality term. Most term structure models (see, e.g., Kim and Wright, 2005; Adrian et al., 2013) lump the Jensen's convexity term into the risk-adjustment component. However, as also noted by Cieslak and Povala (2016), Rebonato and Putyatin (2018), and Berardi et al. (2021), its contribution is time-varying and may well affect our inference, especially during turbulent times.

Formally, we can write the yield on a $\tau$-maturity zero coupon bond, $Y_{t}(\tau)$, as the sum of the average $\mathbb{P}$-expectation of the nominal short rate $E S Y$, a nominal term premium TPY, and the average nominal convexity $C X Y$, all computed over $\tau$ :

$$
Y_{t}(\tau)=E S Y_{t}(\tau)+T P Y_{t}(\tau)+C X Y_{t}(\tau)
$$

Appendix A provides full derivation. Alternatively, we can express $Y_{t}(\tau)$ as the sum of a breakeven or inflation rate $H_{t}(\tau)$, which is the yield on a zero-coupon asset that pays realized inflation over the maturity $\tau$, and a real yield $R_{t}(\tau)$, which is the yield on an inflationprotected security over the same maturity. The model-implied equilibrium breakeven and real rates are also affine in the state variables and could be similarly split into the sum of three components,

$$
\begin{aligned}
& H_{t}(\tau)=E S H_{t}(\tau)+T P H_{t}(\tau)+C X H_{t}(\tau) \\
& R_{t}(\tau)=E S R_{t}(\tau)+T P R_{t}(\tau)+C X R_{t}(\tau) .
\end{aligned}
$$

This means that, overall, a $\tau$-maturity nominal yield is driven by six terms, all computed over $\tau$ : the average $\mathbb{P}$-expectation of short-term inflation $(E S H)$ and short-term real rate $(E S R)$; the inflation term premium $(T P H)$ and the real term premium $(T P R)$; and the average convexity of inflation expectations $(C X H)$ and of real rates $(C X R)$. We now take the model to the data and empirically assess the importance of each of these terms in four major markets. 


\section{Data and preliminary statistics}

We estimate the model using data on nominal yields, breakeven rates, yield volatilities, and macroeconomic expectations spanning the period from January 1999 to December 2018 for the following four markets: the US, the Euro Area, the UK, and Japan. In what follows, we refer to them alternatively as markets or countries, even though the Eurozone is strictly speaking not a country. We provide a detailed description of data sources and transformations in Appendix B.1.

For nominal yields, we use the zero curve from interest rate swap rates with maturities between 2 and 10 years. Among the studies that also use swap rates to fit term structure models, see, for example, Dai and Singleton (2000), Jotikasthira et al. (2015), and Balter et al. (2021). We capture breakeven rates through zero-coupon inflation swap rates, again spanning maturities between 2 and 10 years. ${ }^{6}$ The data start on July 2004 for all countries but Japan, for which they begin in March 2007.

A key ingredient of the model is the simultaneous role of time-varying volatility and macroeconomic expectations in driving yields, which allows us to exploit information on the second moment of yields and on macroeconomic forecasts. For the former, we require the model to fit the realized within-month variance of daily changes in yields at the most liquid maturities of 2, 5, and 10 years. In addition, we use the implied variance of interest rate derivative contracts to proxy for the expected yield variance under the risk-neutral measure. To be precise, we rely on the implied variance in 6-month swaption contracts that give the holder the right to enter a swap with maturities of 2, 5, or 10 years. By incorporating riskadjusted market expectations of nominal yield volatilities, these series prove very useful in identifying the latent variance factor $v$ and the risk premia parameters. For macro forecasts, we use the median 1-year-ahead forecasts of annual CPI growth and annual real GDP growth rates, which are available on a quarterly basis.

\footnotetext{
${ }^{6}$ Inflation swaps are derivative contracts where, at maturity, the protection seller pays the other party the cumulative CPI inflation over the lifespan of the contract. In exchange, the protection buyer pays a predetermined, fixed rate and is known as the synthetic breakeven inflation (BEI) rate. See Fleckenstein et al. (2017) for a formal definition of the zero-coupon inflation swap contract and Haubrich et al. (2012) and Kaminska et al. (2018) for other studies that use such data in the context of term structure models.
} 
We collect summary statistics for the dataset in Table 1. Panel A reports the means and standard deviations of the series in each country, focusing on the 2-, 5-, and 10-year maturities for yields and breakeven rates. The average term structure of yields is upward sloping in all countries, with the difference between the 10-year and 2-year yield ranging from $65 \mathrm{bps}$ for the UK to $128 \mathrm{bps}$ for the US. For breakeven rates, the term structure is flat to downward sloping in Japan, moderately steep at 35 bps in the UK and Euro Area, and steepest at $58 \mathrm{bps}$ for the US. The average term structure of yield volatilities is initially increasing until the 5-year maturity before flattening at the long end. Somewhat similar patterns are observed for implied volatilities, which tend to be some $5-10$ bps higher than the realized ones. Finally, inflation and real GDP growth forecasts vary on average in the 2-3\% range for the US and the UK and are lower at around 1.5\% for the Euro Area. For Japan, consistent with the breakeven rates, inflation forecasts are much smaller at $0.5 \%$.

In Panel $\mathrm{B}$ of the table, we report the results of performing a principal component analysis (PCA) on different groups of series. For each market, we report the percentage of the overall variance that is explained by the first (column 'PC1') and collectively by the second to fourth (columns 'PC2-4') principal components of the correlation matrix of the corresponding group of series. In the first row of the panel, the PCA is on the group of nominal yields and breakeven rates (across all nine maturities). The first factor (PC1) accounts for a sizeable portion of the overall variance, with fractions ranging from $56 \%$ for the UK to $92 \%$ for the Euro Area. All four factors collectively explain more than $99 \%$ of the overall variance in nominal and inflation rates across the four countries. For the volatilities reported in the second row, the evidence is more homogeneous, with PC1 accounting for about $75 \%$ in all countries except the US, where it peaks at $86 \%$. Finally, when combining all 26 series in the last row (nine each for yields and breakeven rates, three each for volatilities, and two for macro factors), the importance of PC1 varies from $43 \%$ for the UK to $62 \%$ for the Euro Area. From these statistics, it is clear that more than a single factor is needed to fully capture the richness in the dynamics of the entire cross section.

Before proceeding with the model estimation, we address a potential issue with the use 
of inflation swap rates; namely, the impact of liquidity risk in their pricing. Some authors contend that these derivative contracts are much more liquid than inflation-linked securities (such as TIPS), as evidenced by nearly flat swap bid-ask spreads during the crisis (see, e.g., Haubrich et al., 2012). Other authors argue instead that the market for inflation-linked bonds (and securities) is not as liquid as the nominal bond market and that such liquidity differential would impact breakeven inflation swap rates negatively (see, e.g., Pflueger and Viceira, 2016). Given that the four countries were hit by market turmoil during the period we study, we want to ensure that a liquidity risk premium does not potentially distort our estimates. For this reason, we follow Pflueger and Viceira (2016) and Bekaert and Ermolov (2021) and identify the liquidity premium by regressing breakeven rates on the 10-year inflation-swap spread (obtained as the breakeven rate minus the difference between the nominal yield and the yield on an inflation-linked security, all at the 10-year maturity) and the country's TED spread (computed as LIBOR minus the yield on a T-bill at 3month maturity), while controlling for the 1-year survey inflation expectation. Details on the procedure are provided in Appendix B.2.

\section{Empirical results}

In this section, we present the results from estimating our term structure model. Section 4.1 discusses the estimation method, and section 4.2 collects a battery of specification tests. In section 4.3, we outline our main empirical results, which are organized around average yield decomposition, time series patterns, and variance decomposition. In section 4.4 we compare our term premia estimates with those from alternative models, while section 4.5 shows that our findings are robust to using Treasury bond yield data. Finally, in section 4.6 we comment on our model-implied long-term equilibrium real rate.

\subsection{Estimation method}

Since the model features unobservable state variables with affine dynamics, we rely on quasimaximum likelihood using the Kalman filter (see Duffee and Stanton, 2012, for a review of 
this methodology). This estimation approach is well suited to accommodate the different frequencies and time periods for which the series are available. The observation equations are obtained by adding an error term to the model-implied expressions for nominal yields, breakeven rates, realized and implied nominal yield variance, and real GDP and inflation forecasts. The state equations are represented by the first-order monthly VAR process implied by the continuous-time model in Eq. (1). In order to better identify the volatility coefficients, we also require the model to match the cross-equation restrictions implied by the conditional variance-covariance matrix of the shocks to the state vector. The estimation is then performed separately for each country. Details on the implementation are provided in Appendix C.

\subsection{Specification tests}

We collect the country-level parameter estimates in Appendix Table F.1. The variance factor $v$ is mean reverting in all four countries, with $\kappa_{11}$ coefficients ranging from 0.22 in the Euro Area and Japan to 0.55 in the UK. In all countries, a significant mean reversion also occurs for the conditional mean of output growth $\mu$, expected inflation $\pi$, and the slope of real rates $s$, whereas the long-term real rate $\ell$ has very low mean reversion, although the coefficient remains statistically significantly different from zero.

Summary statistics on the goodness of fit are reported in Panel A of Appendix Table F.2. The standard deviation of estimation errors in nominal yields ranges from 3 bps for Japan to $8 \mathrm{bps}$ for the UK, while the range is 9 to $15 \mathrm{bps}$ for breakeven inflation rates. The fit of yield volatilities is also rather good, with a standard deviation of estimation errors between 10 and 17 bps. With regard to the macro forecasts, we notice that the fit of real GDP growth is quite accurate, while inflation rate forecasts are relatively harder to match. ${ }^{7}$

To evaluate the ability of the model to capture the dynamics of risk premia in a reasonable way, we report two complementary statistics. First, Panel B of Appendix Table F.2 collects summary statistics on the model-implied maximal Sharpe ratio, which is the Sharpe ratio

\footnotetext{
${ }^{7}$ This fact can be due to a "tension" that arises when simultaneously matching breakeven rates and CPI forecasts. For the US, such tension is especially pronounced during the 2007-2009 crisis, when breakeven rates turned negative while CPI forecasts remained at some $1-1.5 \%$, thereby giving rise to a large forecast error.
} 
that can be attained by a portfolio of bonds spanning the payoff of the implied stochastic discount factor (Duffee, 2010). The maximum ranges from 0.48 for Japan to 2.62 for the US, which reassures us that the model does not deliver implausibly high Sharpe Ratios.

Second, we check whether the model can replicate the extent of deviations from the Expectations Hypothesis (EH) that is found in the data. We resort to Campbell and Shiller's (1991) regressions as a diagnostic test for detecting departures from EH. Specifically, following Wachter (2006) and Joslin and Le (2013), we estimate regression

$$
Y_{t+12}(\tau-1)-Y_{t}(\tau)=\phi_{0}(\tau)+\phi(\tau)\left[\frac{Y_{t}(\tau)-Y_{t}(1)}{\tau-1}\right]+\epsilon_{t+12}(\tau)
$$

on both observed and fitted (i.e., model-implied sample) yields. Moreover, following Dai and Singleton (2002), we compute the model-implied population coefficient $\phi(\tau)$, which is obtained by using the estimated model parameters into the expression

$$
\widehat{\phi}(\tau)=(\tau-1)\left[\frac{\operatorname{Cov}\left\{Y_{t+12}(\tau-1)-Y_{t}(\tau), Y_{t}(\tau)-Y_{t}(1)\right\}}{\operatorname{Var}\left\{Y_{t}(\tau)-Y_{t}(1)\right\}}\right],
$$

where the covariance and variance are expressed in closed form. Finally, we run a Monte Carlo simulation in which we use the estimated model parameters to generate five hundred samples of length 50,000 and calculate $\phi(\tau)$ for each sample. We take the plus/minus onestandard deviation interval around these estimates as the confidence interval for the $\widehat{\phi}(\tau)$ coefficients. Given the well-known small sample biases that plague this regression (Bekaert et al., 1997), we also compute average coefficients across five hundred simulations of small sample size.

Figure 1 displays the corresponding estimates for maturities ranging between 2 and 10 years. Looking at the estimates from the actual data, we observe that the degree of rejection of the EH varies across maturities and countries. All lines become more negative at long maturities; namely, they move away from the value of unity predicted by the EH. For the US and Japan, the slopes are already negative at about -0.5 at short maturities; hence, the EH is rejected everywhere. For the Euro Area, the coefficients lie in positive territory 
until $\tau=6$ years and only become -1 at $\tau=10$ years. Finally, for the UK, the slopes are positive and near unity for short-term yields but become negative thereafter and end up at -1.5 . Turning to the model, we find that the corresponding coefficients on fitted yields are perfectly aligned with those from the actual data. The model-implied projection coefficients also decrease with maturity, reaching between -1 and -2 at long maturities and are statistically significantly different from one. We also confirm the presence of small sample biases, whose importance varies across countries. We conclude that risk premia from the model vary in a way that matches the observed failure of the EH from Eq. (14), contrary to the extant critique of stochastic volatility term structure models (see Dai and Singleton, 2002; Joslin and Le, 2013).

An alternative test of the EH proposed by Campbell and Shiller (1991) looks at whether the slope forecasts long-term changes in short rates in the correct direction. Bekaert et al. (2001) show that the evidence against the EH is generally much weaker under this specification, which is less sensitive to measurement error in the long rate, and argue that the presence of peso problems in small samples can distort the previous test. ${ }^{8}$ Spurred by their work, we estimate the alternative Campbell-Shiller regression

$$
\frac{1}{\tau}\left[\sum_{i=0}^{\tau-1} Y_{t+i \cdot 12}(1)\right]-Y_{t}(1)=\zeta_{0}(\tau)+\zeta(\tau)\left[Y_{t}(\tau)-Y_{t}(1)\right]+e_{t+(\tau-1) \cdot 12}
$$

and report in Table 2 the slope estimates on observed yields $\widehat{\zeta}(\tau)$ at the $\tau=2-, 5$-, 10-year maturities, their $95 \%$ confidence intervals, and the slope estimates on the model-implied yields for the four markets in our study. Under the EH, the slope coefficient $\zeta(\tau)$ should equal unity at all maturities.

As we can see, the extent of rejection of the $\mathrm{EH}$ in the data is now far less clear-cut. For example, while we reject the EH for the US and Euro Area at the 10-year maturity, the confidence intervals are generally wide and include unity at the 2-year maturity (for the Euro Area, marginally not so for the US) and the 5-year maturity. For the UK, the slope

\footnotetext{
${ }^{8}$ Working on a similar set of countries to ours, Bekaert et al. (2007) also use this version of the EH within a VAR approach and detect departures from the EH that, albeit statistically significant, are economically modest.
} 
coefficients are all around unity and the EH is never rejected, while for Japan the opposite holds, with evidence against the EH at all maturities. The same patterns are found in the model estimates. This evidence suggests that, while the $\mathrm{EH}$ is broadly rejected, the incidence of time-varying term premia is not ubiquitously large but rather varies in the cross section of countries, which in turn implies that yield expectations might after all account for much of the variation in the yield curve of some markets.

Lastly, we find that the model fares well at matching short-term nominal rates, which are not used in the estimation but only in bootstrapping the term structure from swap rates. For example, the average correlation between our estimated series and the 6-month LIBOR zero rate is 0.96 in level and 0.57 in monthly changes. The mean and the volatility of the two series are also comparable across all countries. ${ }^{9}$

\subsection{Dissection of yields}

\subsubsection{Average yield components}

Table 3 reports the average estimated yield components at the 2-, 5-, and 10-year maturities for each of the four markets in our study. ${ }^{10}$ The first three columns contain the decomposition of nominal yields of Eq. (11). Across all markets, the level of nominal yields is mostly on account of short-rate expectations under the physical measure, $\operatorname{ESY}(\tau)$, which average about 100 bps for Japan and about 300 bps for the other markets. The term structure of short-rate expectations slopes upward for all markets; it is steepest for Japan (from 38 bps to 157 bps) and least so for the UK (from 298 bps to 357 bps).

Average term premia TPY are positive and steeply increasing with maturity for the US (from 14 bps to $60 \mathrm{bps}$ ) and the UK (from 16 bps to $32 \mathrm{bps}$ ). For the Euro Area, they are essentially null at the 2-year maturity and a meager 16 bps at the long end. In contrast, average term premia in Japan are negative at all horizons and reach a significant -47 bps at

\footnotetext{
${ }^{9}$ The standard deviation of the estimation errors is, by contrast, relatively large when compared to that for other maturities, averaging about 35 bps. However, a Diebold and Mariano (2002) test cannot reject the null hypothesis that model errors are different from those of the hard-to-beat random walk benchmark, with $p$-values of 0.50 for the US, 0.28 for the Euro Area, 0.08 for the UK, and 0.73 for Japan.

${ }^{10}$ Appendix Table F.3 collects the loadings $b$ of nominal yields and the three components of Eq. (11) on the state vector.
} 
the 10-year maturity.

Finally, the convexity component $C X Y$ is (by construction) negative and increasing in absolute terms with maturity. On average, convexity plays a somewhat economically significant role at long maturities for the US ( $-18 \mathrm{bps})$ and the UK ( $-12 \mathrm{bps})$, while it is quite modest for the Euro Area and Japan.

The remaining six columns of Table 3 report the average inflation and real components from Eq. (12)-(13). The term structure of inflation expectations is almost flat, varying from about 300 bps for the UK to only about 80 bps for Japan. This behavior contrasts with the steep average real term structure, which implies that real short-rate expectations become progressively more important at the long end. The inflation term premium increases with maturity, reaching 15 bps for the Euro Area and twice as much (30 bps) for the US and the UK. The real term premium is of comparable size to the inflation term premium for the US, but it is a few basis points for the UK and Euro Area. For Japan, both the inflation and real risk premium are negative and increasingly such with maturity. Lastly, we note that convexity mainly comes from the real side, as the contribution of convexity in inflation is essentially null.

\subsubsection{Time series of yield components}

Figure 2 displays the time series of the decomposed 10-year nominal yield. For the US (Panel A), the estimated term premium peaks at 125 bps in the first part of the sample, ranges between 50 bps and 90 bps for the period 2004 to 2010, and finally declines toward zero by the sample end. Short-rate expectations are characterized by a sustained decline from $6 \%$ in 2000 to about $1.5 \%$ in mid-2016, followed by an upward trend toward values around $3 \%$. The convexity term is, at times, rather substantial. It reaches -55 bps between end-2001 and mid-2003, is smaller during the 2004-2006 expansionary monetary policy, and hits its minimum of -110 bps during the 2008 financial crisis. In the last part of the sample, it shrinks in correspondence with the Fed's unconventional monetary policies. Thus, while the importance of convexity from the numbers in Table 3 appears modest, its magnitude 
compared to the level of yields (for the US, but also for the Euro Area and UK) is all but negligible for prolonged periods.

We compare our estimates of the 10-year term premium with those from the benchmark models of Kim and Wright (2005) (KW) and Adrian et al. (2013) (ACM). ${ }^{11}$ These models are homoskedastic, so they treat the convexity term as a constant. Our average term premium is close to that of $\mathrm{KW}$ (60 bps versus $59 \mathrm{bps}$ ) and considerably lower than that of ACM (108 bps). However, the standard deviation of our estimated term premium is only 40 bps, against 54 bps for KW and 92 bps for ACM. KW use expectations on short-term rates at different time horizons which, as shown by Kim and Orphanides (2012), make short-rate expectations more volatile and stabilize the term premium. ${ }^{12}$ We obtain a similar effect through the use of survey expectations on macro factors, which also allow us to disentangle the real and inflation component of yields and to study the interrelation between macro factors and the term structure. If we relate our term premia with those from the constant volatility models of Christensen and Rudebusch (2012) and Kopp and Williams (2018), ${ }^{13}$ we note that they all share similar paths, although our term premia are lower in absolute terms and much less erratic. Haubrich et al.'s (2012) stochastic volatility model, by contrast, delivers a term premium that is relatively high (about 140 bps between 1982 and 2010) and does not spike around turbulent times. We return to a formal investigation of the source of difference between our term premia and those from competing approaches in Section 4.4 below.

For the Euro Area in Panel B, we again observe a decadal fall in the 10-year yield that is mostly due, until 2012, to a decline in short-rate expectations. However, unlike the US, we do not see a rebound in the last part of the period, as the expectations remain flat at about 1.6\%. Convexity is some negative 20 bps until late 2008, when it jumps to -45 bps during the 2008 crisis and to -30 bps during the European sovereign debt crisis, falling to zero

\footnotetext{
${ }^{11}$ Term premium estimates for the KW and ACM models are frequently updated on the websites of the Federal Reserve (for KW) and the New York Fed (for ACM).

${ }^{12} \mathrm{Li}$ et al. (2017) show that once survey expectations of long-term yields are included in the ACM framework, ACM and KW produce approximately the same term premium estimates.

${ }^{13}$ Both models are based on a modified Nelson and Siegel (1987) framework, which is augmented in Kopp and Williams (2018) by two macroeconomic factors related to the unemployment rate and the inflation gap.
} 
thereafter. The term premium is, by contrast, positive and relatively large, ranging between 70 bps and 100 bps until 2005; it then decreases to nearly zero in 2006, when it starts a steady increase up to the $1 \%$ peak in 2009. Eurozone term premia become negative in 2012 and remain persistently so afterward, reaching values in the -60 to -100 bps range, which almost equal (minus) the level of yield. This pattern has similarities with that in Cohen et al. (2018), who report estimates for the 10-year term premium obtained by applying the ACM model to German government bonds, the macro term structure model of Hördahl and Tristani (2014) to French government bonds, and the Bank of France model (based on Monfort et al., 2017) to OIS rates.

A similar time series behavior of term premia is observed for the UK in Panel C. The series is some 50-60 bps in the early part of the sample and shrinks to few basis points in the years preceding the 2008 financial crisis, consistent with evidence in Joyce et al. (2010) and Malik and Meldrum (2016). ${ }^{14}$ Then, we observe a run-up with a peak at about 100 bps, followed by a decline and a rebound in 2013. By 2015, UK term premia are negative and remain such until the end of the sample, averaging -30 bps or about half those for continental Europe. The pattern of the 10-year convexity term also mirrors the Euro Area quite closely: it reaches some -30 to -40 bps in the early part of the sample and during the 2008 financial crisis, before reverting to zero by 2010 .

Relative to other markets, the expected short rate for Japan (Panel D) is much smaller and smooth, slowly declining from $2 \%$ in 2006 to about $1 \%$ by 2018 . An almost equal contribution to the overall demise of the 10-year nominal yield comes from the term premium component, which is around zero until 2009 when it jumps to some -70 bps and remains persistently negative thereafter, reaching a trough of $-100 \mathrm{bps}$. Our term premium estimates are significantly lower and, conversely, our estimated short-rate expectations higher than those obtained by Imakubo and Nakajima (2015) using a shadow rate model. Unlike the other markets, the convexity term is mostly negligible.

\footnotetext{
${ }^{14}$ According to these and other studies (see also Guimarães, 2012; Joyce et al., 2012), a large fall occurred in the term premium, especially in its inflation component, around 1997, as a consequence of the operational independence given to the Bank of England and the application of the minimum funding requirement, which induced a high demand of index-linked bonds from pension funds.
} 


\subsubsection{Time series of inflation and real components}

Panel A of Figure 3 displays the time series of inflation rate expectations across countries. All series are characterized by a sharp drop during the financial crisis. However, while for the UK and Japan the expectations have reverted back to the pre-crisis levels by the end of the sample, for the US and especially the Euro Area they remain about 50 bps lower.

Panel B shows that real rate expectations have markedly declined in all four markets since 2001. US expectations have wandered quite a bit over the sample, reaching a value of zero from late 2011 until mid-2013 and then again in 2016, but they have recovered to nearly 100 bps in the last period. The UK shares a similar pattern until the 2008 crisis, when expectations sharply dropped; they turned persistently negative in mid-2010, reaching a minimum in 2017 and ending up at -100 bps by the end of the sample. Expectations for the Euro Area and Japan fell to zero by mid-2013 and have remained around that value thereafter.

In Panel C of the figure, we observe that the 10-year inflation term premia for the US, the UK, and the Euro Area all share very similar dynamics. They are mostly positive, volatile in the early years of the sample, spike during the financial crisis, and are relatively flat over the last four years of the sample, with a decline toward zero for the Euro Area at the end of the sovereign debt crisis. For the US, the path of the implied 5-10 year forward inflation term premium (not reported) is similar to that in Abrahams et al. (2016), and their average over the common sample is approximately the same (around $70 \mathrm{bps}$ ). For the UK, our estimated inflation term premium is quite persistent but remains positive, in contrast to the highly volatile and often negative series obtained in Kaminska et al. (2018). For Japan, by contrast, the premium is mainly negative at about -50 bps and much more erratic, reaching a trough at the onset of the financial crisis.

Finally, real term premia (Panel D) are characterized by a distinct downward trend over the sample, which is especially pronounced after the financial crisis. Across all markets, real term premia enter negative territory in 2012 and are negative $50-70$ bps by the sample end, with the exception of the US, whose premium has reverted back to zero in recent 
years. Negative real term premia are consistent with a power utility consumption-based asset pricing model where persistent shocks to consumption growth make long-term inflationindexed bonds a desirable hedge (Campbell et al., 2009).

\subsubsection{Variance decomposition}

In Table 4, we report the model-implied decomposition of the 1-month-ahead forecast error variance of the 2- and 10-year nominal yields. The decomposition is in the spirit of Diebold and Yilmaz (2012); see Appendix E for details. At the 2-year maturity, short-rate expectations account for the vast majority - between $92 \%$ and $94 \%$ - of yield forecast error variance. The term premium accounts, on average, for only a meager $7 \%$ of the variability of the 2 year yield. At the 10-year maturity, the impact of the term premium component increases significantly, with noticeable differences across countries. In particular, it contributes about $28 \%$ of the variability of the forecast error variance in the 10 -year nominal yield of the US, $34 \%$ in the UK and the Euro Area, and a large $50 \%$ in the case of Japan. Nevertheless, short-rate expectations remain by far the most important element in driving the dynamics of long-term yields for all countries but Japan. Even though convexity is sizeable during periods of market turmoil, its role in explaining yield forecast error variance is on average economically large only for Japan. ${ }^{15}$

When breaking down the components into their inflation and real counterparts, we observe that most of the variability comes from the real side, at both short and long maturities. For example, real short-rate expectations and the real term premium account, respectively, for about $54 \%$ and $28 \%$ of the forecast error variance in the 10-year yield averaging across the four markets. The outlier is Japan, for which the combined contribution of inflation expectations and term premium is $39 \%$. This evidence is consistent with Bekaert and Ermolov (2021), who find that it is the variation in real yields that is mostly responsible for total yield variation in France, the UK, and the US and explain this fact through slow-moving risk aversion in an asset-pricing consumption-based habit framework coupled with an inflation

\footnotetext{
${ }^{15}$ These conclusions remain unchanged if we compute the decomposition of the 1-year-ahead variance (not reported for brevity).
} 
model. $^{16}$

\subsection{Why is the term premium component less important?}

The finding that expected short rates are mostly responsible for driving bond yields and their decline over the sample runs contrary to previous international evidence by Wright (2011), Jotikasthira et al. (2015), and Mönch (2019). In this section, we drill down into the reasons for these differences.

We first verify that our result is not sample-specific. To this end, we take as a benchmark Wright's (2011) model (WR) and fit it using the two-step estimation approach adopted in his work.Like ours, WR is a five-factor affine term structure model with macro factors. However, unlike our model, WR does not feature stochastic volatility, and the factors are represented by the first three principal components of yields and two macro variables that are proxied by the exponentially weighted moving average of quarterly inflation and GDP growth. We extract the three principal components from our yield curves but, in order to facilitate the comparison with our estimates, we use as macro factors the 1-year-ahead survey forecasts of inflation and GDP growth (see Appendix B.1).

Panel A of Table 5 compares the means and standard deviations of the 10-year short-rate expectations and term premium obtained from the estimation of WR with those provided by our model. We find that, apart from Japan, the average level of the components is relatively similar for the two models, especially for the US and Euro Area. Instead, the standard deviation of the components is significantly different, since in WR the volatility of short-rate expectations is much lower and the volatility of the term premium much higher than that estimated by our stochastic volatility model. ${ }^{17}$ Panel B of the table shows that, consistent with the evidence in Wright (2011), the term premium from the WR model accounts for half or more of the 1-month-ahead forecast error variance of the 10-year yield (computed as in

\footnotetext{
${ }^{16}$ For the US and Euro Area, we are able to assess the robustness of our conclusions to using longer-term forecasts, as SPF forecasts are freely available at the 10-year and 5-year horizons, respectively. When using these series in the estimation in place of the 1-year forecast, we continue to find that short-rate expectations are responsible for most yield variation. However, inflation term premia become more volatile and important as the horizon of the forecast series lengthens.

${ }^{17}$ According to Bauer et al. (2014) and Bauer and Hamilton (2018), the estimation approach in Wright (2011) may lead to overestimating the variability of term premia because of a small sample bias in the estimate of the mean reversion coefficients.
} 
Table 4) in all countries but the Euro Area. This evidence reassures us that the difference between our results and those in prior literature on the role of short-rate expectations and term premia in explaining the variability of long-term yields is not driven by the specific sample period or input series.

To trace the source of the difference back to our model features, notably the joint inclusion of macro expectations and stochastic volatility, we compare our estimates to those from three alternative affine models. For the sake of brevity, we limit our analysis to the US market.

The first alternative model is the well known five-factor Gaussian framework we have referred to as ACM. Unlike our approach, ACM has no stochastic volatility and macro factors, and the state variables are represented by the first five principal components of yields. We fit the model to our nominal yield data, using the ACM two-step estimation technique.

We further consider two nested versions of our model, namely (i) a Gaussian four-factor model with macro factors but without stochastic volatility, defined as GM4, and (ii) a stochastic volatility four-factor model without the macro factor $\mu$, defined as SV4. GM4 includes as unobservable factors the conditional mean of output growth $\mu$, the expected inflation rate $\pi$, the slope of the real term structure $s$, and the long-term real interest rate $\ell$. We require the model to fit nominal yields and breakeven inflation rates, with maturities between 2 and 10 years and 1-year-ahead survey forecasts for real GDP growth and CPI inflation rate. SV4 assumes that the four unobservable factors are given by the variance factor $v$, the expected inflation rate $\pi$, the slope of the real term structure $s$, and the long-term real interest rate $\ell$. We fit the model using nominal yields and breakeven inflation rates, with maturities between 2 and 10 years and realized variance and implied variance of yields with maturities 2, 5 and 10 years.

We plot the resulting 10-year nominal term premium in Panel A of Figure 4. We note that the standard deviations of the term premium are 99 bps for ACM, 46 bps for GM4, and 56 bps for SV4, versus 40 bps for our model. Furthermore, when we decompose the variance of the 10-year yield we find that ACM explains the variability of yields mainly as 
a term premium effect, while GM4, SV4, and our model provide a different interpretation, with short-rate expectations being the main driver. In particular, the fraction of the 1month-ahead forecast error variance of the 10-year nominal yield explained by the term premium component is equal to $81 \%$ for ACM, $40 \%$ for GM4, $31 \%$ for SV4, and $28 \%$ for our model. Overall, the comparative analysis between our five-factor model and the two nested four-factor versions GM4 and SV4 vis-à-vis the five-factor ACM model allows us to appreciate how different model features lead to different inferences about term premia and their role in driving nominal yield volatility. These findings show that anchoring the estimation to macroeconomic forecasts of inflation and real growth and accounting for timevarying volatility reduces the variability in the resulting nominal term premium and shifts the lion's share of yield fluctuations toward yield expectations, which contradicts the previous (mainly Gaussian-based) evidence.

Our comparison so far has been among term premia from competing affine models. A natural question is whether the dynamics captured by our model could be alternatively identified by adopting a non-linear framework. To offer some evidence in this direction, we estimate a four-factor model of the type in Feldhütter et al. (2018) on our data for yields and yield variances. Panel $\mathrm{B}$ in Figure 4 contrasts the 10-year nominal term premium obtained from the estimation of Feldhütter et al. (2018) with that from our model. We observe that, although the average term premia are not too different (52 vs 60 bps), the standard deviation from the nonlinear model is significantly higher (82 vs $40 \mathrm{bps}$ ). The model of Feldhütter et al. (2018) attributes about $56 \%$ of the nominal yield forecast error variance to term premia, and the remaining $44 \%$ to short-rate expectations. In terms of estimation accuracy, Feldhütter et al.'s (2018) model provides a very good fit for yields, with an average (across maturities) standard deviation of errors of only $3.85 \mathrm{bps}$, while estimation errors for yield variances are large when compared to those obtained by our model. Overall, this evidence suggests that while the two approaches share similarities, they are not close substitutes, with our stochastic volatility framework faring relatively better at capturing yield second moment dynamics.

As yet another related exercise, in Appendix D we report that our estimated volatility 
factor shares similar patterns with the yield volatility from a reduced-form, regime-switching model.

\subsection{Results using Treasury bond yield data}

We assess the robustness of our findings to using bond yields in place of zero rates implied by swap rates. For the US, we use yields from Gurkaynak et al. (2007 and 2008) on both nominal Treasury bonds and TIPS. For the Euro Area, we use yields from OAT nominal and inflation-linked bonds issued by France, a major European country with a stable and mature inflation-linked bond program. For the UK, we gather nominal Gilts and inflation-linked Gilts. Further details are provided in Appendix B.1.

Appendix Table F.4 reports in the first two columns the correlations in level and in first difference, respectively, of each of the yield components at the 10-year maturity, estimated using either bond yields or swap rates. All components are very highly positively correlated, with values ranging between 0.88 and 1 in level and between 0.71 and 0.98 in first difference. The third column reports the model-implied decomposition of the 1-month-ahead forecast error variance of the 10-year nominal yield when estimating the model on bond yields. The main conclusion of the paper continues to hold: the expected short rate component $(E S Y)$ accounts for the bulk - above $70 \%$ - of forecast error variance of the 10-year nominal yield.

\subsection{Equilibrium real rate}

In this section, we comment on the long-run "equilibrium" real interest rate that is implied by the model, defined as the average expected real short rate over a five-year period starting five years ahead. This rate is a proxy for the Wicksellian "natural" rate, which represents the long-run real interest rate consistent with a closed output gap and stationary inflation.

In the literature, the estimation of the equilibrium real interest rate has been carried out through either a macroeconomic approach, based on the relationship between output, inflation, and interest rates (see, among others, Laubach and Williams, 2003), or a financial approach, which relies only on data for the yield curve (see, e.g., Christensen and Rude- 
busch, 2019). The two approaches generate substantially different equilibrium rates, so that considerable uncertainty remains about the "correct" level. Our approach provides a bridge between these two approaches, as it is based on a finance-based, no-arbitrage model integrated with macro factors. In addition, unlike previous methodologies, our estimates are consistent with both the first and second moments of interest rates since we allow for stochastic volatility.

The solid blue line in Figure 5 displays the implied estimates of the 5- to 10-year real forward rate for the four markets in our study. All series are characterized by a marked decline over the sample period. Average rates are highest for the Euro Area and the US at around $1.5 \%$, followed by Japan $(1.2 \%)$ and the UK $(0.9 \%)$. For the US and the UK, we can compare our series to a "model-free" benchmark, namely the 5- to 10-year real forward rate that is implicit in the market price of inflation-protected securities. To be precise, the dash-dotted line in Panel A displays the forward rate from the US TIPS yield curve calculated by Gurkaynak et al. (2008). The two series move remarkably closely together (with a correlation of 0.96), although the TIPS line is some 50 to 60 bps higher on average, mostly reflecting TIPS illiquidity in the early part of the sample (D'Amico et al., 2018). For the UK in Panel C, we show the forward rate computed from the yield curve of UK Index-Linked Gilts published by the Bank of England. Again, the correlation with our model-implied equilibrium rate is high at 0.89, although significant differences appear in the 2001-2004 and 2009-2012 periods. Both rates turn negative by 2015, with the Gilts series exhibiting an even more extreme drop to nearly -200 bps.

\section{Analysis of comovement}

In this section, we exploit more forcefully the cross-sectional dimension of our study by examining cross-country comovement in yields. As a first step in this direction, we ask whether our model is capable of matching the extent of yield correlation in the data, or whether instead significant excess yield correlation is left out. To this end, Panel A of Figure 6 displays the scatter plot of correlations in observed nominal yields ( $\rho_{y}$, Y-axis) against 
those in fitted nominal yields ( $\rho_{\widehat{y}}, \mathrm{X}$-axis). Each correlation is computed between yields of the same maturity but different country, for a total of 54 observations (9 maturities and 6 combinations). The estimates from a linear fit are also displayed (with standard errors in parentheses), along with the 45-degree line. From the plot, it is clear that the model does remarkably well at capturing yield correlations, with an R-squared of 0.99, a slope coefficient very close to one, and an intercept term that, albeit statistically significant, is economically very small at -0.05 .

Since (fitted) yields are linear combinations of the latent state variables, international bond yield comovement depends on the correlation structure of the countries' state vectors and on the country- and maturity-specific loadings $b(\tau)$. In Section 5.1, we report on the factor structure in the state variables, while Section 5.2 looks at volatility spillovers.

\subsection{Yield correlation and factor structure}

Even if we do not explicitly model cross-country relations, the estimated state variables might and indeed do follow common patterns in the cross section. ${ }^{18}$ We examine the strength of such linkages by performing a principal component analysis within each variable across countries. We find a factor structure that is particularly pronounced in $v$ and $\mu$, whose first principal components account for nearly $70 \%$ of overall variance. For $\pi, \ell$, and $s$, the importance of the first principal component is lower, at about 50-60\%.

Spurred by this evidence, we investigate its implications for modelling international comovement. We regard the full model as "unconstrained," as it allows for country-specific state variables, and test how a "constrained" version that assumes an international factor structure in the state variables fares in matching observed yield correlations. The scope of this analysis is to quantify differences in the relative importance of global versus local drivers of the yield curve and to show the extent to which a low-dimensional factor structure brings us closer to match actual correlations. To isolate the importance of each ingredient of our model, we do this separately for the instantaneous variance $v$, the macro expectations $\mu$ and

\footnotetext{
${ }^{18}$ We could, in principle, model the dynamics of the full $(20 \times 1)$ state vector and then carry a joint estimation that pools data from all countries. While theoretically appealing, the increase in noise and computational challenge from estimating the very large number of parameters that such a full system commands would likely destroy our inference.
} 
$\pi$, and the instantaneous real rate components $s$ and $\ell$.

We begin by imposing a one-factor structure in Panel B of Figure $6{ }^{19}$ The leftmost plot in the panel shows that a one-factor assumption in $v$ is largely rejected by the data, with a nearly null R-squared. A similar picture emerges for the drivers of instantaneous real rates $s$ and $\ell$, in the rightmost panel, for which the goodness of fit is a modest 0.01. Finally, the middle plot shows that assuming a single factor in macro expectations captures about half the variance in observed correlations but typically underestimates a wealth of them, as testified by the 0.52 slope coefficient.

In Panel $\mathrm{C}$ of Figure 6, we repeat the same experiment for a two-factor structure. ${ }^{20}$ For aggregate uncertainty $v$ and macro expectations, this structure raises the R-squared to about 0.70 , and the points line up more closely with the 45-degree line. For the real rate, by contrast, the two-factor assumption is still not enough, as the R-squared remains a modest 0.09 , with several country pair correlations largely mis-estimated. In all, this analysis highlights differences in the relative importance of global versus local drivers of the yield curve, and shows the extent to which a low-dimensional factor structure gets us closer to matching the comovement in the data.

\subsection{Volatility spillovers}

Yield comovement arises not only from contemporaneous common cross-country variation within a given state variable, but also from the full (lead/lag) correlation structure across countries, which ultimately generates cross-country predictability in yields and their components. There is growing evidence that US shocks play a special role in driving international asset market comovement. Lagged US stock market returns significantly predict non-US returns, while the converse does not hold (Rapach et al., 2013). Fed policy announcements

\footnotetext{
${ }^{19}$ For $v$, this is done as follows. We first compute the first principal component of $v$ across countries and call it $P C 1^{v}$. Next, we recompute fitted yields using the model-estimated coefficients but replacing each country $i$ 's $v_{t}^{i}$ series with $\left(L 1_{i}^{v} \times P C 1^{v}\right)$, where $L 1_{i}^{v}$ is the country $i$ 's element in the first eigenvector of the PCA for $v$. For $\mu$ and $\pi$ (and analogously for $s$ and $\ell$ ), we simultaneously replace a country $i$ 's $\mu_{t}^{i}$ and $\pi_{t}^{i}$ series with its one-factor analogue - that is, $\left(L 1_{i}^{\mu} \times P C 1^{\mu}\right)$ and $\left(L 1_{i}^{\pi} \times P C 1^{\pi}\right)$ respectively - and use them along with the other domestic variables to reconstruct fitted bond yields.

${ }^{20}$ For $v$, it means we compute the first two principal components $P C 1^{v}$ and $P C 2^{v}$ and construct fitted yields using the full model estimates but replace $v_{t}^{i}$ with $\left(L 1_{i}^{v} \times P C 1^{v}+L 2_{i}^{v} \times P C 2^{v}\right)$, where $L 2_{i}^{v}$ is now the element pertaining to country $i$ in the second eigenvector for $v$. We proceed similarly for the other variables.
} 
induce shifts in non-US equity risk premia (Brusa et al., 2020) and strongly affect international market comovement in sovereign CDS markets (Caporin et al., 2020). In contrast, the Japanese equity market deviates systematically from the predictability patterns observed in other developed countries (see Andersen et al., 2021, and references therein). Our setting provides a natural framework to investigate whether these conclusions extend to the yield curve.

To provide a full characterization of cross-country linkages, we again rely on the Diebold and Yilmaz (2012) variance decomposition. In the decomposition, we work directly on the state variables by fitting a $\operatorname{VAR}(1)$ on the pooled estimated state vector consisting of 20 variables (five for each of the four countries). Next, we compute the fraction of the 1-monthahead forecast error variance of a country's 10-year nominal yield that is explained by both its own and foreign yield components. The fraction is on account of both the strength of cross-country correlations and the variability of a component relative to the overall yield variance. See Appendix E for details on the methodology.

Panel A of Table 6 reports the resulting variance breakdown (in percentage terms) across all nominal yield components, where each column corresponds to a given country and totals $100(\%)$. In analogy with the results in Table 4, we find that the largest contributions come mainly from short-rate expectations, followed by term premia and lastly convexity terms. In general, for a given country, the dominant entries within each group among $E S Y$, $T P Y$, and $C X Y$ are those from own-country components. This is the case, for example, for US short-rate expectations (36.42\%) and UK term premia (14.75\%). However, there are noteworthy exceptions, such as the role of US expectations and term premia in explaining other countries' yield variance.

The total spillover index implied from the panel (i.e., the ratio of the sum of external fractions to the total) is nearly $60 \%$, which underscores the presence of strong nominal yield comovements. When breaking down the index into its inflation and real portions, we discover that the latter is mostly responsible for the spillovers (50\% out of $60 \%$ ). This result is again in line with Bekaert and Ermolov (2021), who find that the covariance between real yields 
across countries is the main source of yield correlation.

In Panel B of the table, we summarize the extent of directional comovement through the net spillover measure. Each row of the panel adds up to zero, and the entries are computed from Panel A as the difference between the percentage of yield variance that a country exports to other countries minus the percentage it imports. It is unequivocal that the US is by far the strongest exporter of shocks to the long end of the nominal yield curve, with an overall $13.84 \%$ net contribution. About three-fourths of it is transmitted through short-rate expectations, with term premia spillovers accounting for the rest. The UK market is also an overall transmitter, with $E S Y$ and $T P Y$ having comparable magnitudes. The Euro Area is on average a recipient of shocks in short-rate expectations and especially term premia. Finally, the Japanese market is the top net importer of volatility shocks at about $-13 \%$, most of which comes from the expectations component. The real/inflation breakdown again confirms that the largest effects are observed among real components.

\section{Conclusion}

What drives the yield curve? Why do interest rates move over time and in the cross section of countries? In this paper, we contribute to knowledge of these fundamental questions by using a model that ties together unobservable yield factors, timely macroeconomic forecasts, and yield volatility. We require the model to match the time series and cross section of nominal and inflation-linked yields to learn about the relative importance of the real and inflation components. In addition, our estimation incorporates information about the realized and implied volatility of yields, which allows us to both capture second moment fluctuations and better identify risk premia.

We fit the model to data from the US, the Euro Area, the UK, and Japan. We confirm prior evidence that term premia vary over time and increase with bond maturity but find that short-rate expectations are by far the dominant driver of nominal yield variability. Over the sample, we observe a marked decline in real short-rate expectations and term premia that turn negative in recent years. We also separately identify the role of time-varying volatility 
in the expression for yields and document a convexity term that is relatively large during periods of high aggregate uncertainty.

Exploiting the panel dimension of our study, we investigate the strength of yield comovement and international spillovers. We find relatively strong comovements that mainly originate from the real components of yields and document that the US and the UK are net exporters of volatility shocks. 


\section{Appendix}

\section{A. Yield decomposition}

From the partial differential equation whose solution provides the time $t$ equilibrium price of the unit zero coupon bond in Eq. (9) we obtain the time $t$ instantaneous forward rate for date $t+\tau$, $f_{t}(\tau)=\frac{1}{F_{t}(\tau)} \frac{\partial F_{t}(\tau)}{\partial t}$, as

$$
f_{t}(\tau)=y_{t}+B^{\prime}(\tau) K\left(\Theta-X_{t}\right)-B^{\prime}(\tau) \Sigma\left(\Lambda_{0}+\Lambda_{1} X_{t}\right)-\frac{1}{2} B^{\prime}(\tau)\left(\Sigma S_{t} \Sigma^{\prime}\right) B(\tau) .
$$

Rearranging terms, this expression can also be written as

$$
\begin{array}{r}
f_{t}(\tau)=\left[y_{t}+D^{\prime}(\tau) K\left(\Theta-X_{t}\right)\right]+\left[B^{\prime}(\tau)-D^{\prime}(\tau)\right] K\left(\Theta-X_{t}\right) \\
-B^{\prime}(\tau) \Sigma\left(\Lambda_{0}+\Lambda_{1} X_{t}\right)-\frac{1}{2} B^{\prime}(\tau)\left(\Sigma S_{t} \Sigma^{\prime}\right) B(\tau) .
\end{array}
$$

where $D^{\prime}(\tau)=\delta^{\prime} K^{-1}\left(\mathrm{I}-e^{-K \tau}\right)$. The first term in brackets on the right-hand side of the equation is the time $t$ instantaneous expectation of the short rate at $t+\tau$ under the $\mathbb{P}$ measure, $\mathrm{E}^{\mathbb{P}}\left[y_{t}(\tau)\right] \equiv$ $y_{t}+D^{\prime}(\tau) K\left(\Theta-X_{t}\right)$.

The difference between the instantaneous forward rate and short-rate expectation in Eq. (A.2) is generally defined as the "forward term premium" (see, for example, Dai and Singleton, 2002; Kim and Wright, 2005). However, in order to isolate the "mechanical" effect of bond convexity, which can be significant for long-term yields in a stochastic volatility environment, we adopt a more restricted definition for the time $t$ forward term premium on a $\tau$-maturity bond, $\operatorname{FTP}_{t}(\tau)$ :

$$
F T P_{t}(\tau)=f_{t}(\tau)-\mathrm{E}^{\mathbb{P}}\left[y_{t}(\tau)\right]-c_{t}(\tau)
$$

where $c_{t}(\tau)=-\frac{1}{2} B^{\prime}(\tau)\left(\Sigma S_{t} \Sigma^{\prime}\right) B(\tau)$ is the instantaneous convexity term.

Taking the integral of both sides of Eq. (A.3) and dividing by $\tau$, we obtain an expression for the yield term premium: $T P Y_{t}(\tau)=\frac{1}{\tau} \int_{t}^{t+\tau} F T P_{t}(u) d u$. Similarly, we define the average expectation of the short rate between $t$ and $t+\tau$ as $E S Y_{t}(\tau)=\frac{1}{\tau} \int_{t}^{t+\tau} \mathrm{E}^{\mathbb{P}}\left[y_{t}(u) d u\right]$ and the average convexity between $t$ and $t+\tau$ as $C X Y_{t}(\tau)=\frac{1}{\tau} \int_{t}^{t+\tau} c_{t}(u) d u$. The yield on a $\tau$-maturity zero coupon bond is the sum of these three components (Eq. (11)).

\section{B. Data description and transformation}

\section{B.1. Data source}

For nominal yields, we use interest rate swap rates with maturities between 2 and 10 years. The data source is Bloomberg. The tickers of the series are USSW (US), EUSA (Euro Area), BPSW (UK), and JYSW (Japan). In the construction of the data set, we also use LIBOR rates for the 6-month maturity, with tickers: US0006M (US), EUR006M (Euro Area), BP0006M (UK), and 
JY0006M (Japan). Swap rates are the yields that determine the semi-annual payments in the fixed leg of the swap contract until maturity. For the purpose of the model estimation, we convert them into zero-coupon bond yields using the standard methodology (see Hull, 2018, Section 7.6).

As a measure of implied volatility, we use the implied variance in 6-month swaption contracts that give the holder the right to enter a swap with maturities of 2,5 , or 10 years. The source is Bloomberg (tickers USSV0A (US), EUSV0A (Euro Area), and JYSV0A (Japan)) and Datastream (ticker ICUK6M (UK)).

For macro forecasts, we use the median 1-year-ahead forecasts of annual CPI growth and annual real GDP growth rates, which are available on a quarterly basis. Specifically, we use the Philadelphia Survey of Professional Forecasters for the US, the ECB Survey of Professional Forecasters for the Eurozone, the Bank's Monetary Policy Committee survey for the UK, and the JCER ESP Forecast for Japan. ${ }^{21}$

We capture breakeven rates through zero-coupon inflation swap rates, again spanning maturities between 2 and 10 years. The data are from Bloomberg and start from July 2004 for all countries but Japan, for which they begin in March 2007. The tickers are USSWI (US), EUSWI (Euro Area), BPSWIT (UK), and JYSWIT (Japan).

In Section 4.5, we use data on Treasury bond yields for the US, the UK and the Euro Area. Yields on US nominal Treasury bonds are from Gurkaynak et al. (2007) and yields on US TIPS are from Gurkaynak et al. (2008). For the UK, we gather nominal Gilts and inflation-linked Gilts from the Bank of England. For the Euro Area, we use yields on French OAT nominal and inflation-linked bonds from Bloomberg. The OAT nominal yield series span the whole January 1999 to December 2018 period, with maturities ranging from 2 to 10 years (mnemonic GFRN). For OAT inflationlinked yields, we obtain artificial 2- to 10-year series from the yield-to-maturity of all available inflation-linked bond issues that are linked to the Eurozone Consumer Price Index ex-Tobacco (OATe; menomonic GFRGEN). The individual bonds start in January 2005 and become overall progressively more numerous as new emissions are issued and some of the bonds reach maturity. Since the inflation-linked bonds pay coupons, we fit a cubic spline each day by associating each yield-to-maturity to the bond's modified duration. The shortest artificial maturity varies over the sample depending on the modified duration of the nearest maturing bond.

\section{B.2. Liquidity premium of inflation swaps}

We isolate the effect of liquidity on breakeven rates through the following procedure. Let $H_{t}(\tau)$ be the time $t \tau$-year zero-coupon breakeven rate for a given country. We regress $H_{t}(\tau)$ on the following three country-specific variables:

- $X_{1, t} \equiv\left(H_{t}(10)-\left(Y_{t}(10)-I L_{t}(10)\right)\right.$, the "basis" or inflation swap spread at the 10-year maturity, where $Y_{t}(10)$ is the 10-year nominal rate and $I L_{t}(10)$ is the yield on a 10-year

\footnotetext{
${ }^{21}$ For Japan, the series are average (not median) forecasts, and are available since April 2004. We are thankful to the Japan Center for Economic Research for sharing their data with us.
} 
inflation-linked security; ${ }^{22}$

- $X_{2, t} \equiv$ Libor $_{3 m, t}-$ Tbill $_{3 m, t}$, the TED spread for that country;

- $X_{3, t}$ is the 1-year-ahead CPI inflation expectation from survey data (Federal Reserve Bank of Philadelphia Survey of Professional Forecasters).

For each $H_{t}(\tau)$, we run the regression

$$
H_{t}(\tau)=a+b_{1} X_{1, t}+b_{2} X_{2, t}+b_{3} X_{3, t}+e_{\tau, t}
$$

We define the liquidity premium as

$$
L P_{t}(\tau)=\left(-\widehat{b}_{1} X_{1, t}-\widehat{b}_{2} X_{2, t}\right)-\min \left\{-\widehat{b}_{1} X_{1, t}-\widehat{b}_{2} X_{2, t}\right\}
$$

and add this premium to the inflation swap spreads, so that the implied real rate $R_{t}(\tau)$ is effectively diminished by $L P_{t}(\tau)$.

Figure B.1 displays the time series of the average (across maturities) liquidity premium, as defined in Eq. (B.2). The premium averages between 20 and 50 bps, with distinct spikes during the 2008 financial crisis and, for the Euro Area, also during the 2011-2012 sovereign debt crisis.

\section{State-space representation of the model}

For each country, our system is comprised of 26 observation equations and five state equations. The 26 observation equations are composed by: (i) 9 equations for nominal yields with maturities from 2 to 10 years; (i) 9 equations for breakeven rates with maturities from 2 to 10 years; (iii) 3 equations for the implied variance of yields, which is affine in $X_{t}$ and is calculated as

$$
V_{t}(\tau)=b^{\prime}(\tau)\left(\Sigma S_{t} \Sigma^{\prime}\right) b(\tau)
$$

with maturities 2, 5, and 10 years; (iv) 3 equations for the realized variance of nominal yield changes, which is obtained from Eq. (C.3) by setting $\Lambda_{t}=0$ for the same maturities of 2, 5, and 10 years; and (v) 2 equations for the expectations of the macroeconomic variables under the physical measure, which are also affine in $X_{t}$ :

$$
\begin{aligned}
\mathrm{E}\left[\ln \frac{p(\bar{\tau})}{p(0)} \mid I_{t}\right] & =A_{p}(\bar{\tau})+B_{p}(\bar{\tau}) X_{t} \\
\mathrm{E}\left[\ln \frac{q(\bar{\tau})}{q(0)} \mid I_{t}\right] & =A_{q}(\bar{\tau})+B_{q}(\bar{\tau}) X_{t} .
\end{aligned}
$$

We treat the median SPF forecasts of the 1-year-ahead CPI inflation rate and real GDP growth rate as observable proxies for Eq. (C.4) and Eq. (C.5), respectively (therefore with the forecast

\footnotetext{
${ }^{22}$ For the US, we use the 10-year yield on TIPS from Gurkaynak et al. (2008); for the UK, we use the yield on the 10-year inflation-linked Gilt obtained from the Bank of England website; for the Euro Area, we use the yield on Thomson Reuter's German Inflation Linked Generic Government Bond (mnemonic GEIL10Y); for Japan, we use Thomson Reuter's redemption yield on Japan Government Inflation Linked (mnemonic TRJPI10).
} 
horizon $\bar{\tau}$ equal to 1$)$.

Given that the expressions listed above are all affine in the latent factors $X_{t}$, the set of observation equations is obtained by adding a vector of observation errors $e_{t}$ and can be compactly written as:

$$
Z_{t}=\alpha_{0}(\eta)+\alpha_{1}(\eta) X_{t}+e_{t},
$$

where $Z_{t}$ collects the 26 observable series at time $t$, and $\alpha_{0}(26 \times 1)$ and $\alpha_{1}(26 \times 5)$ solve the equations above and depend on the full set of model parameters $\eta$. We assume $e_{t}$ to be normally distributed and homoskedastic.

As breakeven rates for the US, the Euro Area and the UK start only in July 2004, for the period January 1999 to June 2004 the system is composed of 17 measurement equations. For Japan, breakeven rates start in March 2007, while the macro factors are available only since April 2004. This implies that macro-related state variables are not identified before April 2004 and thus, in the estimation, data on yields and yield volatility from January 1999 to March 2004 are used only to warm up the filter. Therefore, the system for Japan comprises 17 measurement equations for the period April 2004 to February 2007 and 26 equations starting in March 2007.

The five state equations are composed of the discrete time (monthly) equivalent of the continuous time model in Eq. (1). The transformation is obtained by exploiting the solution to the stochastic differential equations that describe the dynamics of the variables, as in Christoffersen et al. (2014). The conditionally affine nature of the process implies that $X_{t}$ follows a Markov Vector Autoregressive process:

$$
X_{t}=\gamma_{0}(\eta)+\gamma_{1}(\eta) X_{t-1}+u_{t},
$$

where $\gamma_{0}(5 \times 1)$ and $\gamma_{1}(5 \times 5)$ also depend on the full set of model parameters $\eta$. An important feature of the model is the presence of time-varying conditional volatility that is driven by the state variables. This implies that the shock $u_{t}$ is hetereroskedastic, with a conditional variance that is affine in $X_{t}$ :

$$
\operatorname{Var}_{t}\left(u_{t}\right)=\omega_{0}(\eta)+\omega_{1}(\eta) X_{t-1} .
$$

The parameters of the state-space model are estimated by maximum likelihood, with an approximate Kalman filter algorithm to calculate the values of the unobserved state variables (see Duan and Simonato, 1999; Duffee and Stanton, 2012; Christoffersen et al., 2014).

\section{Comparison with regime-switching approach}

Jumps or regime switches are natural candidate modelling approaches to capture swings in volatility. A direct comparison with our conditionally Gaussian model is not as straightforward, especially since the introduction of these features to simultaneously fit nominal yields, breakeven rates and yield volatilities would entail a very large parameter space.As a way to offer a cue in this direction, we estimate a two-state model for changes in the 10-year US nominal yield with either constant probabilities (as in Hamilton, 1989) or time-varying probabilities (as in Perez-Quiros and Tim- 
mermann, 2000), where the conditioning set consists of a lag, the implied 10-year T-note variance and 1-year GDP survey expectation. Appendix Figure D.1 displays the resulting conditional standard deviations together with our estimated US latent volatility factor (i.e., $\sqrt{v_{t}}$ ). As we can see, the two series spike around the same time periods, with positive correlations at 0.33 to 0.67 , respectively. We take this evidence as reassuring that our conditionally Gaussian model does share similar dynamics with those from a (reduced-form) regime-switching approach. A proper comparison would, of course, need a fully-fledged regime-switching model that ensures estimates consistent with no-arbitrage pricing of both nominal and real yields. We leave this task for future research.

\section{E. Variance and covariance decomposition}

We obtain the model-implied decomposition of the 1-month-ahead forecast error variance of nominal yields by adapting to our setup the framework of Diebold and Yilmaz (2012), which in turn relies on the generalized VAR framework of Koop et al. (1996) and Pesaran and Shin (1998).

Ignoring constant terms, Eq. (1) implies that our state vector follows a 5 -variable covariance stationary $\operatorname{VAR}(1)$ of the form $X_{t}=\Phi X_{t-1}+\varepsilon_{t}$, where $\varepsilon_{t} \sim\left(0, \Upsilon_{t}\right)$ is the vector of heteroskedastic disturbances. Let $\Upsilon$ be the long-run variance-covariance matrix of $\varepsilon_{t}$. The moving average representation is $X_{t}=\sum_{h=0}^{\infty} A_{h} \varepsilon_{t-h}$, where the $5 \times 5$ matrices $A_{h}$ obey the recursion $A_{h}=\Phi A_{h-1}$, with $A_{0}$ being the identity matrix and $A_{h}=0$ for $h<0$.

From Eq. (10), the $\tau$-year nominal yield is affine in the state vector, with slope $b_{Y} \equiv b(\tau)$ (we suppress the $\tau$ index to minimize notational clutter). The $M A(\infty)$ representation implies that the $H$-month-ahead forecast error of the nominal yield is

$$
e_{t+H, t}^{Y}=\sum_{h=0}^{H-1} b_{Y}^{\prime} A_{h} \varepsilon_{t+1+h} .
$$

We are interested in breaking down the variance of $e_{t+H, t}^{Y}$ into the fraction accounted for by each of the three terms in Eq. (11), and in turn by each of the six terms in Eq. (12)-(13). The nine terms are also affine in $X_{t}$. Let $b_{i}$ denote the slope coefficient on $X_{t}$ for a given term $i$, with $i=\{E S Y, T P Y, C X Y\}$ or $i=\{E S H, \ldots, C X R\}$. Following Diebold and Yilmaz (2012), we compute the fraction of variance of $e_{t+H, t}^{Y}$ explained by term $i$ as

$$
\theta_{i}(H)=\frac{\left(b_{i}^{\prime} \Upsilon b_{i}\right)^{-1} \sum_{h=0}^{H-1}\left(b_{Y}^{\prime} A_{h} \Upsilon b_{i}\right)^{2}}{\sum_{h=0}^{H-1}\left(b_{Y}^{\prime} A_{h} \Upsilon A_{h}^{\prime} b_{Y}\right)}
$$

where the denominator is the variance of $e_{t+H, t}^{Y}$. Since the variables are not orthogonalized, we normalize each entry of the variance decomposition by their sum:

$$
\theta_{i}^{*}(H)=\frac{\theta_{i}(H)}{\sum_{i} \theta_{i}(H)}
$$

We set $H=1$, which implies a one-month forecast horizon. However, using a higher $H$ leads to 
similar conclusions.

For the analysis of comovement, we proceed in a similar fashion with the caveat that we can no longer use the model-implied estimates, as they do not contain cross-country terms. We therefore estimate a $\operatorname{VAR}(1)$ model on the pooled state vector $\widetilde{X}_{t}$ consisting of 20 variables (five for each of the four countries). Let $\widetilde{\Upsilon}$ and $\widetilde{A}_{h}$ be the resulting $(20 \times 20)$ error variance-covariance matrix and moving average coefficient matrices, respectively. We re-define the coefficients $b_{i}$ of each country component so that they load on the corresponding country variable within $\widetilde{X}_{t}$. We denote with $\widetilde{b}_{i}$ the resulting $(20 \times 1)$ vectors.

The fraction of $H$-month forecast error variance of the yield of a given country that is explained by term $i$, with $i=\left\{E S Y_{U S}, \ldots, C X Y_{J P}\right\}$, is

$$
\widetilde{\theta}_{i}(H)=\frac{\left(\widetilde{b}_{i}^{\prime} \widetilde{\Upsilon} \tilde{b}_{i}\right)^{-1} \sum_{h=0}^{H-1}\left(\widetilde{b}_{Y}^{\prime} \widetilde{A}_{h} \widetilde{\Upsilon}^{\tilde{b}_{i}}\right)^{2}}{\sum_{h=0}^{H-1}\left(\widetilde{b}_{Y}^{\prime} \widetilde{A}_{h} \widetilde{\Upsilon} \widetilde{A}_{h}^{\prime} \widetilde{b}_{Y}\right)} .
$$

Since the variables are not orthogonalized, we normalize each entry of the variance decomposition by their sum for the yield of a given country:

$$
\widetilde{\theta}_{i}^{*}(H)=\frac{\widetilde{\theta}_{i}(H)}{\sum_{i} \widetilde{\theta}_{i}(H)} .
$$

Again, we set $H=1$. We proceed similarly for the inflation and real components $\left\{E S H_{U S}, \ldots\right.$, $\left.C X R_{J P}\right\}$. The total spillover index and net spillovers are then computed as in Diebold and Yilmaz (2012).

\section{F. Parameter estimates and further results}

Table F.1 reports maximum likelihood estimates of the model parameters. Table F.2 collects summary statistics for the fitting errors. Table F.3 reports the model-implied factor loadings (that is, the $b$ coefficients in the affine expressions) for nominal yields and their components from Eq. (11) at the 2-, 5-, and 10-year maturity. Finally, Table F.4 presents the results from fitting the model on Treasury bond data. 


\section{References}

Abrahams, M., Adrian, T., Crump, R. K., Moench, E., and Yu, R. (2016). Decomposing real and nominal yield curves. Journal of Monetary Economics, 84:182-200.

Adrian, T., Crump, R., and Moench, E. (2013). Pricing the term structure with linear regressions. Journal of Financial Economics, 110:110-138.

Adrian, T. and Wu, H. (2009). The term structure of inflation expectations. Federal Reserve Bank of New York Staff Report No. 362.

Ahn, D.-H., Dittmar, R. F., and Gallant, A. R. (2002). Quadratic term structure models: Theory and evidence. The Review of Financial Studies, 15(1):243-288.

Andersen, T. G., Todorov, V., and Ubukata, M. (2021). Tail risk and return predictability for the Japanese equity market. Journal of Econometrics, 222(1):344-363.

Ang, A., Bekaert, G., and Wei, M. (2008). The term structure of real rates and expected inflation. Journal of Finance, 63(2):797-849.

Ang, A. and Piazzesi, M. (2003). A no-arbitrage vector autoregression of term structure dynamics with macroeconomic and latent variables. Journal of Monetary Economics, 50(4):745-787.

Balter, A. G., Pelsser, A., and Schotman, P. C. (2021). What does a term structure model imply about very long-term interest rates? Journal of Empirical Finance, 62:202-219.

Bansal, R., Tauchen, G., and Zhou, H. (2004). Regime shifts, risk premiums in the term structure, and the business cycle. Journal of Business 83 Economic Statistics, 22(4):396-409.

Barr, D. G. and Priestley, R. (2004). Expected returns, risk and the integration of international bond markets. Journal of International Money and Finance, 23(1):71-97.

Bauer, M., Rudebusch, G., and Wu, J. (2014). Term premia and inflation uncertainty: Empirical evidence from an international panel dataset: Comment. American Economic Review, 104(1):323-37.

Bauer, M. D. and Hamilton, J. D. (2018). Robust bond risk premia. The Review of Financial Studies, 31(2):399-448.

Bekaert, G. and Ermolov, A. (2021). International yield co-movements. Working Paper, Columbia Business School.

Bekaert, G., Hodrick, R. J., and Marshall, D. A. (1997). On biases in tests of the expectations hypothesis of the term structure of interest rates. Journal of Financial Economics, 44(3):309-348.

Bekaert, G., Hodrick, R. J., and Marshall, D. A. (2001). Peso problem explanations for term structure anomalies. Journal of Monetary Economics, 48(2):241-270.

Bekaert, G., Wei, M., and Xing, Y. (2007). Uncovered interest rate parity and the term structure. Journal of International Money and Finance, 26(6):1038-1069.

Berardi, A., Brown, R. H., and Schaefer, S. M. (2021). Bond risk premia: The information in really long-maturity forward rates. Working Paper, London Business School.

Berardi, A. and Plazzi, A. (2019). Inflation risk premia, yield volatility and macro factors. Journal of Financial Econometrics, 17(3):397-431.

Bikbov, R. and Chernov, M. (2010). No-arbitrage macroeconomic determinants of the yield curve. Journal of Econometrics, 159(1):166-182.

Bikbov, R. and Chernov, M. (2013). Monetary policy regimes and the term structure of interest rates. Journal of Econometrics, 174(1):27-43. 
Brusa, F., Savor, P., and Wilson, M. (2020). One central bank to rule them all? Review of Finance, 24(2):263-304.

Campbell, J., Shiller, R., and Viceira, L. (2009). Understanding inflation-indexed bond markets. Brookings Papers on Economic Activity, 1:79-120.

Campbell, J. Y. and Shiller, R. J. (1991). Yield spreads and interest rate movements: A bird's eye view. Review of Economic Studies, 58(3):495-514.

Caporin, M., Pelizzon, L., and Plazzi, A. (2020). Does monetary policy impact international market co-movement? Swiss Finance Institute Working Paper No. 17-47.

Chen, R.-R., Liu, B., and Cheng, X. (2010). Pricing the term structure of inflation risk premia: Theory and evidence from TIPS. Journal of Empirical Finance, 17(4):702-721.

Chib, S. and Kang, K. H. (2012). Change-points in affine arbitrage-free term structure models. Journal of Financial Econometrics, 11(2):302-334.

Christensen, J. H. and Rudebusch, G. D. (2012). The response of interest rates to US and UK quantitative easing. Economic Journal, 122(564):385-414.

Christensen, J. H. and Rudebusch, G. D. (2019). A new normal for interest rates? Evidence from inflation-indexed debt. Review of Economics and Statistics, 101(5):933-949.

Christoffersen, P., Dorion, C., Jacobs, K., and Karoui, L. (2014). Nonlinear Kalman filtering in affine term structure models. Management Science, 60:2248-2268.

Chun, A. L. (2010). Expectations, bond yields, and monetary policy. Review of Financial Studies, $24(1): 208-247$.

Cieslak, A. and Povala, P. (2016). Information in the term structure of yield curve volatility. Journal of Finance, 71(3):1393-1436.

Clarida, R. H., Sarno, L., Taylor, M. P., and Valente, G. (2006). The role of asymmetries and regime shifts in the term structure of interest rates. The Journal of Business, 79(3):1193-1224.

Cohen, B. H., Hördahl, P., and Xia, F. D. (2018). Term premia: Models and some stylised facts. BIS Quarterly Review, September 2018.

Crump, R. K., Eusepi, S., and Moench, E. (2018). The term structure of expectations and bond yields. Federal Reserve Bank of New York Staff Report No. 775.

Dahlquist, M. and Hasseltoft, H. (2013). International bond risk premia. Journal of International Economics, 90(1):17-32.

Dai, Q. and Singleton, K. J. (2000). Specification analysis of affine term structure models. Journal of Finance, 55(5):1943-1978.

Dai, Q. and Singleton, K. J. (2002). Expectation puzzles, time-varying risk premia, and affine models of the term structure. Journal of Financial Economics, 63(3):415-441.

Dai, Q., Singleton, K. J., and Yang, W. (2007). Regime shifts in a dynamic term structure model of U.S. treasury bond yields. The Review of Financial Studies, 20(5):1669-1706.

D'Amico, S., Kim, D. H., and Wei, M. (2018). Tips from TIPS: The informational content of Treasury inflation-protected security prices. Journal of Financial and Quantitative Analysis, $53(1): 395-436$.

Diebold, F. X. and Mariano, R. S. (2002). Comparing predictive accuracy. Journal of Business $\&$ Economic Statistics, 20(1):134-144. 
Diebold, F. X. and Yilmaz, K. (2012). Better to give than to receive: Predictive directional measurement of volatility spillovers. International Journal of Forecasting, 28(1):57-66.

Duan, J.-C. and Simonato, J.-G. (1999). Estimating and testing exponential-affine term structure models by kalman filter. Review of Quantitative Finance and Accounting, 13(2):111-135.

Duffee, G. (2002). Term premia and interest rate forecasts in affine models. Journal of Finance, $57: 405-443$.

Duffee, G. (2010). Sharpe ratios in term structure models. Working paper, Johns Hopkins University.

Duffee, G. and Stanton, R. (2012). Estimation of dynamic term structure models. Quarterly Journal of Finance, 2:1-51.

Feldhütter, P., Heyerdahl-Larsen, C., and Illeditsch, P. (2018). Risk premia and volatilities in a nonlinear term structure model. Review of Finance, 22(1):337-380.

Fleckenstein, M., Longstaff, F. A., and Lustig, H. (2017). Deflation risk. Review of Financial Studies, 30(8):2719-2760.

Garcia, J. A. and Werner, S. E. (2016). Bond risk premia, macroeconomic factors and financial crisis in the Euro area. ECB Working Paper No. 1938.

Guimarães, R. (2012). What accounts for the fall in UK ten-year government bond yields? Bank of England Quarterly Bulletin, Q3.

Gurkaynak, R., Sack, B., and Wright, J. (2007). The U.S. Treasury yield curve: 1961 to the present. Journal of Monetary Economics, 54:2291-2304.

Gurkaynak, R., Sack, B., and Wright, J. (2008). The TIPS yield curve and inflation compensation. American Economics Journal: Macroeconomics, 93:10-24.

Hamilton, J. D. (1989). A new approach to the economic analysis of nonstationary time-series and the business-cycle. Econometrica, 57(2):357-384.

Haubrich, J., Pennacchi, G., and Ritchken, P. (2012). Inflation expectations, real rates, and risk premia: Evidence from inflation swaps. Review of Financial Studies, 25:1588-1629.

Hördahl, P., Sobrun, J., and Turner, P. (2016). Low long-term interest rates as a global phenomenon. BIS Working paper N.574.

Hördahl, P. and Tristani, O. (2012). Inflation risk premia in the term structure of interest rates. Journal of the European Economic Association, 10(3):634-657.

Hördahl, P. and Tristani, O. (2014). Inflation risk premia in the Euro area and the United States. International Journal of Central Banking, 10(3):1-47.

Hull, J. C. (2018). Options, Futures, and Other Derivatives. Pearson Education, River, New Jersey.

Imakubo, K. and Nakajima, J. (2015). Estimating inflation risk premia from nominal and real yield curves using a shadow-rate model. Bank of Japan Working Paper No. 15.

Joslin, S. and Le, A. (2013). Interest rate volatility and no-arbitrage affine term structure models. Working Paper, University of Southern California.

Joslin, S., Priebsch, M., and Singleton, K. J. (2014). Risk premiums in dynamic term structure models with unspanned macro risks. Journal of Finance, 69(3):1197-1233.

Jotikasthira, C., Le, A., and Lundblad, C. (2015). Why do term structures in different currencies co-move? Journal of Financial Economics, 115(1):58-83. 
Joyce, M. A., Kaminska, I., and Lildholdt, P. (2012). Understanding the real rate conundrum: An application of no-arbitrage models to the UK real yield curve. Review of Finance, 16(3):837-866.

Joyce, M. A., Lildholdt, P., and Sorensen, S. (2010). Extracting inflation expectations and inflation risk premia from the term structure: A joint model of the UK nominal and real yield curves. Journal of Banking and Finance, 34(2):281-294.

Kaminska, I., Liu, Z., Relleen, J., and Vangelista, E. (2018). What do the prices of UK inflationlinked securities say on inflation expectations, risk premia and liquidity risks? Journal of Banking and Finance, 88:76-96.

Kim, D. and Wright, J. (2005). An arbitrage-free three-factor term structure model and the recent behavior of long-term yields and distant-horizon forward rates. Federal Reserve Board Working Paper No. 2005-33.

Kim, D. H. and Orphanides, A. (2012). Term structure estimation with survey data on interest rate forecasts. Journal of Financial and Quantitative Analysis, 47(1):241272.

Koop, G., Pesaran, M., and Potter, S. M. (1996). Impulse response analysis in nonlinear multivariate models. Journal of Econometrics, 74(1):119-147.

Kopp, E. and Williams, P. D. (2018). A macroeconomic approach to the term premium. IMF Working Paper No. 18/140.

Laubach, T. and Williams, J. C. (2003). Measuring the natural rate. Review of Economics and Statistics, 85:1063-1070.

Leippold, M. and Wu, L. (2002). Asset pricing under the quadratic class. The Journal of Financial and Quantitative Analysis, 37(2):271-295.

Li, C., Meldrum, A. C., and Rodriguez, M. (2017). Robustness of long-maturity term premium estimates. Feds notes, Board of Governors of the Federal Reserve System.

Ludvigson, S. C. and Ng, S. (2009). Macro factors in bond risk premia. Review of Financial Studies, 22(12):5027-5067.

Malik, S. and Meldrum, A. (2016). Evaluating the robustness of UK term structure decompositions using linear regression methods. Journal of Banking and Finance, 67:85-102.

Mönch, E. (2019). The term structures of global yields. BIS Papers 102.

Monfort, A., Pegoraro, F., Renne, J.-P., and Roussellet, G. (2017). Staying at zero with affine processes: An application to term structure modelling. Journal of Econometrics, 201(2):348 366.

Nelson, C. R. and Siegel, A. F. (1987). Parsimonious modeling of yield curves. Journal of Business, $60: 473-489$

Perez-Quiros, G. and Timmermann, A. (2000). Firm size and cyclical variations in stock returns. The Journal of Finance, 55(3):1229-1262.

Pesaran, H. and Shin, Y. (1998). Generalized impulse response analysis in linear multivariate models. Economics Letters, 58(1):17-29.

Pflueger, C. E. and Viceira, L. M. (2016). Return Predictability in the Treasury Market: Real Rates, Inflation, and Liquidity, chapter 10, pages 191-209. John Wiley \& Sons, Ltd.

Piazzesi, M. (2010). Affine term structure models. In Ait-Sahalia, Y. and Hansen, L., editors, Handbook of financial econometrics, pages 691-766. Elsevier, Amsterdam.

Rapach, D. E., Strauss, J. K., and Zhou, G. (2013). International stock return predictability: What is the role of the United States? The Journal of Finance, 68(4):1633-1662. 
Rebonato, R. and Putyatin, V. (2018). The value of convexity: A theoretical and empirical investigation. Quantitative Finance, 18(1):11-30.

Wachter, J. A. (2006). A consumption-based model of the term structure of interest rates. Journal of Financial Economics, 79(2):365-399.

Wright, J. H. (2011). Term premia and inflation uncertainty: Empirical evidence from an international panel dataset. American Economic Review, 101(4):1514-34. 
Table 1

Summary statistics and factor analysis.

\begin{tabular}{|c|c|c|c|c|c|c|c|c|c|}
\hline \multicolumn{10}{|l|}{ Panel A: Summary Statistics } \\
\hline \multirow[b]{2}{*}{ Series } & \multirow[b]{2}{*}{ maturity } & \multicolumn{2}{|c|}{ US } & \multicolumn{2}{|c|}{ Euro Area } & \multicolumn{2}{|c|}{ UK } & \multicolumn{2}{|c|}{ Japan } \\
\hline & & Avg & Std & Avg & Std & Avg & Std & Avg & Std \\
\hline \multirow[t]{3}{*}{ Nominal Yields } & 2-year & 264.2 & 198.5 & 215.8 & 175.4 & 316.5 & 215.8 & 35.4 & 31.4 \\
\hline & 5 -year & 332.6 & 178.5 & 262.9 & 174.8 & 352.9 & 195.7 & 64.5 & 45.5 \\
\hline & 10-year & 392.5 & 160.6 & 319.2 & 166.4 & 381.8 & 167.1 & 117.2 & 60.3 \\
\hline \multirow[t]{3}{*}{ Breakeven rates } & 2-year & 184.4 & 82.6 & 150.1 & 61.2 & 278.9 & 67.4 & 35.7 & 97.7 \\
\hline & 5 -year & 215.8 & 50.0 & 165.2 & 50.3 & 293.1 & 39.8 & 33.5 & 75.3 \\
\hline & 10-year & 242.2 & 35.0 & 187.5 & 40.5 & 312.6 & 27.4 & 33.2 & 59.3 \\
\hline \multirow[t]{3}{*}{ Realized Yield Volatilities } & 2-year & 71.4 & 43.0 & 49.4 & 30.2 & 57.5 & 28.8 & 13.5 & 11.0 \\
\hline & 5 -year & 90.4 & 40.6 & 60.4 & 27.0 & 67.8 & 24.6 & 26.9 & 18.2 \\
\hline & 10-year & 91.5 & 37.5 & 60.8 & 23.8 & 68.7 & 21.4 & 38.4 & 21.3 \\
\hline \multirow[t]{3}{*}{ Implied Yield Volatilities } & 2-year & 76.6 & 38.2 & 71.0 & 26.0 & 73.0 & 29.3 & 19.7 & 14.5 \\
\hline & 5-year & 94.9 & 35.9 & 77.1 & 23.1 & 77.5 & 20.5 & 34.8 & 21.9 \\
\hline & 10-year & 96.8 & 33.1 & 66.7 & 22.9 & 77.3 & 16.3 & 47.9 & 19.6 \\
\hline Inflation rate forecast & 1-year & 219.9 & 24.1 & 161.9 & 30.1 & 208.5 & 50.8 & 48.0 & 77.3 \\
\hline Real GDP growth forecast & 1-year & 261.2 & 80.0 & 153.3 & 92.4 & 221.8 & 75.9 & 180.6 & 60.3 \\
\hline
\end{tabular}

Panel B: Factor Analysis

\begin{tabular}{|c|c|c|c|c|c|c|c|c|c|}
\hline \multirow[b]{2}{*}{ Series } & \multirow[b]{2}{*}{ Maturity } & \multicolumn{2}{|c|}{ US } & \multicolumn{2}{|c|}{ Euro Area } & \multicolumn{2}{|c|}{ UK } & \multicolumn{2}{|c|}{ Japan } \\
\hline & & PC1 & $\mathrm{PC} 2-4$ & PC1 & $\mathrm{PC} 2-4$ & $\mathrm{PC} 1$ & $\mathrm{PC} 2-4$ & PC1 & $\mathrm{PC} 2-4$ \\
\hline Nom. Yields and Bkv. Rates & All & 75.8 & 24.0 & 92.2 & 7.7 & 56.4 & 43.4 & 66.1 & 33.2 \\
\hline Yield Volatilities & All & 86.1 & 13.1 & 75.9 & 22.2 & 74.5 & 24.0 & 72.6 & 25.5 \\
\hline All series & All & 55.2 & 40.3 & 62.0 & 32.7 & 43.1 & 49.1 & 58.2 & 36.8 \\
\hline
\end{tabular}

The table contains summary statistics on the data used in estimation. Panel A reports means and standard deviations (in basis points) for the time series of nominal yields, breakeven rates, realized and implied volatilities of yield changes, all at the 2-, 5-, and 10-year maturity. The last rows are for the median 1-year forecasts of inflation rate and real GDP growth. Panel B reports the result of a principal component analysis (PCA) on different groups of series. We show the percentage of the overall variance that is explained by the first (column ' $\mathrm{PC} 1$ ') and collectively by the second to fourth (column 'PC2-4') principal components of the correlation matrix of the corresponding group of series. The time period is January 1999 to December 2018 for yields, while breakeven rates start in July 2004. For Japan, breakeven rates start in March 2007, while 1-year-ahead forecasts of inflation rate and real GDP growth start in April 2004. The PCA is performed on the sample period over which all of the series are available. 
Table 2

Campbell-Shiller slope coefficient estimates.

\begin{tabular}{lccccccc}
\hline Horizon $\tau$ & \multicolumn{3}{c}{ Panel A: US } & & \multicolumn{3}{c}{ Panel B: Euro Area } \\
\cline { 2 - 4 } \cline { 6 - 8 }$($ years $)$ & estimate & $95 \%$ C.I. & model & & estimate & $95 \%$ C.I. & model \\
\hline 2 & 0.30 & {$[-0.30 ; 0.91]$} & 0.57 & & 0.92 & {$[0.30 ; 1.54]$} & 0.57 \\
5 & 1.37 & {$[0.80 ; 1.93]$} & 1.65 & & 1.21 & {$[0.76 ; 1.67]$} & 1.15 \\
10 & 1.24 & {$[1.18 ; 1.31]$} & 1.23 & & 1.35 & {$[1.24 ; 1.45]$} & 1.30
\end{tabular}

\begin{tabular}{|c|c|c|c|c|c|c|}
\hline \multirow{2}{*}{$\begin{array}{l}\text { Horizon } \tau \\
\text { (years) }\end{array}$} & \multicolumn{3}{|c|}{ Panel C: UK } & \multicolumn{3}{|c|}{ Panel D: Japan } \\
\hline & estimate & 95\% C.I. & model & estimate & 95\% C.I. & model \\
\hline 2 & 0.84 & {$[0.15 ; 1.54]$} & 0.25 & 0.33 & {$[0.12 ; 0.54]$} & 0.44 \\
\hline 5 & 1.00 & {$[0.41 ; 1.58]$} & 0.8 & 0.36 & {$[-0.02 ; 0.75]$} & 0.40 \\
\hline 10 & 1.15 & {$[0.79 ; 1.52]$} & 0.94 & 0.47 & {$[-0.03 ; 0.98]$} & 0.48 \\
\hline
\end{tabular}

The table reports the slope coefficients from estimating Eq. (16) at the $\tau=2,5,10$ year maturity on the actual yield data, their $95 \%$ confidence intervals based on Newey-West standard errors with $(\tau-1) \cdot 12$ lags, and the corresponding model estimates for the four markets in our study. The sample period is January 1999 to December 2018. 
Table 3

Dissection of yields.

\begin{tabular}{|c|c|c|c|c|c|c|c|c|c|}
\hline $\begin{array}{l}\text { Maturity } \\
\text { (years) }\end{array}$ & $\begin{array}{c}\text { Expected } \\
\text { short rate } \\
E S Y\end{array}$ & $\begin{array}{c}\text { Term } \\
\text { premium } \\
T P Y\end{array}$ & $\begin{array}{l}\text { Convexity } \\
\text { CXY }\end{array}$ & $\begin{array}{c}\text { Expected } \\
\text { inflation rate } \\
E S H\end{array}$ & $\begin{array}{c}\text { Expected } \\
\text { real short rate } \\
E S R\end{array}$ & $\begin{array}{l}\text { Inflation term } \\
\text { premium } \\
T P H\end{array}$ & $\begin{array}{l}\text { Real term } \\
\text { premium } \\
\quad T P R\end{array}$ & $\begin{array}{c}\text { Convexity } \\
\text { inflation } \\
\mathrm{CXH}\end{array}$ & $\begin{array}{c}\text { Convexity } \\
\text { real } \\
C X R \\
\end{array}$ \\
\hline \multicolumn{10}{|c|}{ Panel A: United States } \\
\hline 2 & 253 & 14 & -1 & 246 & 7 & 3 & 11 & 0 & -1 \\
\hline 5 & 308 & 30 & -4 & 248 & 60 & 12 & 18 & -1 & -3 \\
\hline 10 & 351 & 60 & -18 & 244 & 107 & 27 & 33 & -2 & -16 \\
\hline \multicolumn{10}{|c|}{ Panel B: Euro Area } \\
\hline 2 & 216 & 0 & 0 & 187 & 29 & 4 & -4 & 0 & 0 \\
\hline 5 & 261 & 6 & -2 & 190 & 71 & 9 & -3 & 0 & -2 \\
\hline 10 & 312 & 16 & -8 & 193 & 119 & 15 & 1 & -1 & -7 \\
\hline \multicolumn{10}{|c|}{ Panel C: United Kingdom } \\
\hline 2 & 298 & 16 & 0 & 284 & 14 & 10 & 6 & 0 & 0 \\
\hline 5 & 325 & 25 & -2 & 292 & 33 & 21 & 4 & 0 & -2 \\
\hline 10 & 357 & 32 & -12 & 296 & 61 & 31 & 1 & -1 & -11 \\
\hline \multicolumn{10}{|c|}{ Panel D: Japan } \\
\hline 2 & 38 & -2 & 0 & 77 & -39 & 3 & -5 & 0 & 0 \\
\hline 5 & 86 & -16 & -1 & 80 & 6 & -1 & -15 & 0 & -1 \\
\hline 10 & 157 & -47 & -5 & 94 & 63 & -17 & -30 & -1 & -4 \\
\hline
\end{tabular}

The table reports the average estimated components of nominal yields as defined in Eq. (11)-(13) at the 2-, 5-, and 10-year maturity for the four markets in our study over the sample period January 1999 to December 2018. For Japan, the sample period starts in April 2004. Entries are expressed in basis points. 
Table 4

Variance decomposition of yield components.

\begin{tabular}{|c|c|c|c|c|c|c|c|c|}
\hline \multirow[b]{2}{*}{ Component } & \multicolumn{4}{|c|}{ 2-year } & \multicolumn{4}{|c|}{ 10-year } \\
\hline & US & Euro Area & UK & Japan & US & Euro Area & UK & Japan \\
\hline Expected short rate & 93.40 & 93.11 & 92.19 & 93.49 & 71.56 & 65.91 & 65.78 & 48.52 \\
\hline Term premium & 6.60 & 6.89 & 7.81 & 6.51 & 28.44 & 34.08 & 34.22 & 49.69 \\
\hline Convexity & 0.00 & 0.00 & 0.00 & 0.01 & 0.00 & 0.01 & 0.00 & 1.78 \\
\hline Expected inflation rate & 14.26 & 5.06 & 5.29 & 14.24 & 9.40 & 4.75 & 6.69 & 15.73 \\
\hline Expected real short rate & 79.13 & 88.05 & 86.90 & 79.25 & 62.17 & 61.16 & 59.09 & 32.79 \\
\hline Inflation term premium & 0.46 & 0.41 & 0.38 & 1.72 & 3.90 & 3.96 & 4.55 & 23.24 \\
\hline Real term premium & 6.14 & 6.48 & 7.43 & 4.79 & 24.54 & 30.12 & 29.67 & 26.45 \\
\hline Inflation rate convexity & 0.00 & 0.00 & 0.00 & 0.00 & 0.00 & 0.00 & 0.00 & 0.43 \\
\hline Real rate convexity & 0.00 & 0.00 & 0.00 & 0.01 & 0.00 & 0.01 & 0.00 & 1.35 \\
\hline
\end{tabular}

The table reports the model-implied decomposition of the 1-month-ahead forecast error variance of the 2- and 10-year nominal yields for the four markets in our study over the sample period January 1999 to December 2018. For Japan, the sample starts in April 2004. Entries are expressed in percentage terms. 
Table 5

Comparison with Wright (2011) Gaussian model.

\begin{tabular}{|c|c|c|c|c|c|c|c|c|c|}
\hline \multicolumn{10}{|c|}{ Panel A: Dissection of the 10-year yield } \\
\hline & & \multicolumn{4}{|c|}{ Avg } & \multicolumn{4}{|c|}{ Std } \\
\hline & & US & Euro Area & UK & Japan & US & Euro Area & UK & Japan \\
\hline \multirow[t]{2}{*}{ Yield } & Model & 396 & 322 & 380 & 105 & 153 & 162 & 155 & 60 \\
\hline & Wright & 397 & 322 & 379 & 107 & 158 & 172 & 158 & 59 \\
\hline \multirow[t]{2}{*}{ Expected short rate } & Model & 351 & 312 & 357 & 157 & 120 & 108 & 128 & 39 \\
\hline & Wright & 343 & 302 & 333 & 198 & 77 & 87 & 84 & 26 \\
\hline \multirow[t]{2}{*}{ Term premium } & Model & 60 & 16 & 32 & -47 & 40 & 59 & 37 & 24 \\
\hline & Wright & 54 & 20 & 46 & -92 & 85 & 88 & 75 & 34 \\
\hline
\end{tabular}

Panel B: Variance decomposition of the 10-year yield with Wright model

\begin{tabular}{lcccc} 
& US & Euro Area & UK & Japan \\
\hline Expected short rate & 49.55 & 62.41 & 45.80 & 33.60 \\
Term premium & 50.45 & 37.59 & 54.20 & 66.40
\end{tabular}

The table provides a comparison of our model with the Gaussian model of Wright (2011) ('Wright'). Panel A reports statistics (average and standard deviation, in basis points) on the 10-year nominal yield and its components from either our model ('Model') or 'Wright' for the four markets in our study over the sample period January 1999 to December 2018. For Japan, the sample period starts in April 2004. Panel B reports the variance decomposition (in percentage terms) from 'Wright'. 
Table 6

Analysis of international volatility spillovers.

\begin{tabular}{lcccc}
\hline \multicolumn{5}{l}{ Panel A: International variance decomposition } \\
\hline & & & & \\
Component & US & Euro Area & UK & Japan \\
\hline$E S Y_{U S}$ & 36.42 & 23.89 & 26.67 & 25.53 \\
$E S Y_{E A}$ & 12.89 & 24.78 & 13.72 & 10.58 \\
$E S Y_{U K}$ & 18.67 & 18.32 & 26.60 & 11.98 \\
$E S Y_{J P}$ & 1.45 & 1.23 & 0.39 & 22.17 \\
$T P Y_{U S}$ & 13.58 & 10.00 & 11.12 & 7.98 \\
$T P Y_{E A}$ & 3.38 & 9.27 & 3.82 & 2.55 \\
$T P Y_{U K}$ & 10.39 & 10.25 & 14.75 & 4.03 \\
$T P Y_{J P}$ & 2.86 & 2.19 & 2.69 & 15.07 \\
$C X Y_{U S}$ & 0.18 & 0.00 & 0.01 & 0.00 \\
$C X Y_{E A}$ & 0.12 & 0.03 & 0.13 & 0.06 \\
$C X Y_{U K}$ & 0.02 & 0.00 & 0.03 & 0.02 \\
$C X Y_{J P}$ & 0.04 & 0.03 & 0.08 & 0.04
\end{tabular}

Total spillover index nominal: 59.27

Total spillover index inflation: 8.67

Total spillover index real: 50.60

Panel B: International net spillovers

\begin{tabular}{|c|c|c|c|c|}
\hline Component & US & Euro Area & UK & Japan \\
\hline Y & 13.84 & -4.67 & 3.76 & -12.94 \\
\hline$E S Y$ & 10.77 & -1.56 & 2.05 & -11.25 \\
\hline$T P Y$ & 3.12 & -3.17 & 1.76 & -1.70 \\
\hline$C X Y$ & -0.04 & 0.07 & -0.05 & 0.02 \\
\hline$E S H$ & 0.82 & -2.24 & 0.22 & 0.48 \\
\hline$E S R$ & 9.95 & 0.68 & 1.83 & -11.73 \\
\hline$T P H$ & -0.23 & -0.49 & -0.72 & 1.20 \\
\hline$T P R$ & 3.35 & -2.68 & 2.48 & -2.90 \\
\hline$C X H$ & 0.00 & 0.00 & 0.00 & 0.01 \\
\hline$C X R$ & -0.04 & 0.07 & -0.05 & 0.01 \\
\hline
\end{tabular}

The table collects the results from the analysis of international spillovers. Panel A reports the fraction (in percentage terms) of the 1-month-ahead forecast error variance of the 10-year nominal yield that is explained by all yield components (including those from other markets) for the four markets in our study and the total spillover index for nominal yields and its inflation/real breakdown, following the methodology in Appendix E. Panel B reports the implied net volatility spillovers (in percentage terms) in yields and their components, followed by the inflation/real breakdown. 


\section{Figure 1}

Deviations from the Expectations Hypothesis.

The figure displays the regression coefficients $\phi(\tau)$ of the Campbell and Shiller (1991) regression of Eq. (14) for the four markets in our study over the sample period from January 1999 (April 2004 for Japan) to December 2018. We report the coefficients estimated by running the regression on either actual yields or fitted yields, and the model-implied population coefficient generated by Eq. (15). The dotted lines are the one-standard deviation upper and lower bounds for the model-implied population coefficient. These are obtained by running a Monte Carlo simulation in which we use the model-estimated parameters to generate five hundred samples of length 50,000 and calculate the regression coefficients for each of them. The dash-dot lines denote averages of the slope coefficients across five hundred simulations of small sample size. Panel A plots the coefficients for the US, Panel B for the Euro Area, Panel C for the UK and Panel D for Japan.

Panel A: United States

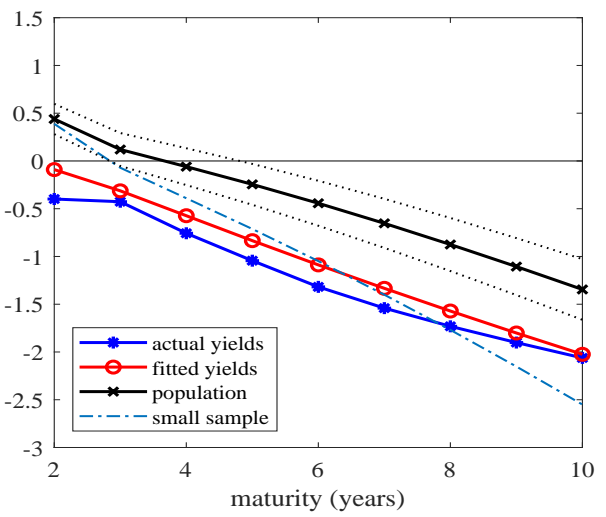

Panel C: United Kingdom

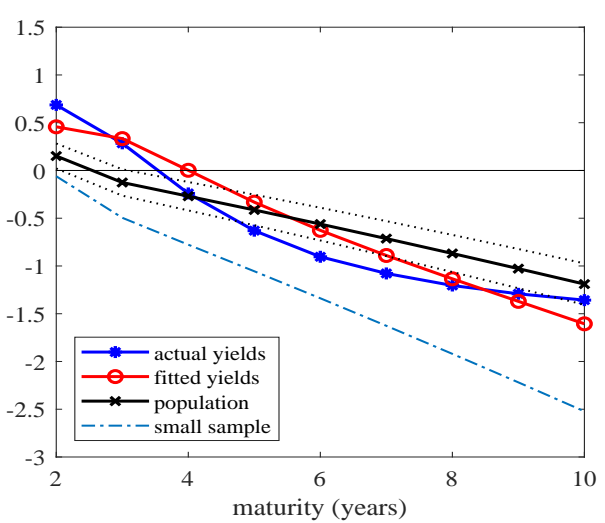

Panel B: Euro Area

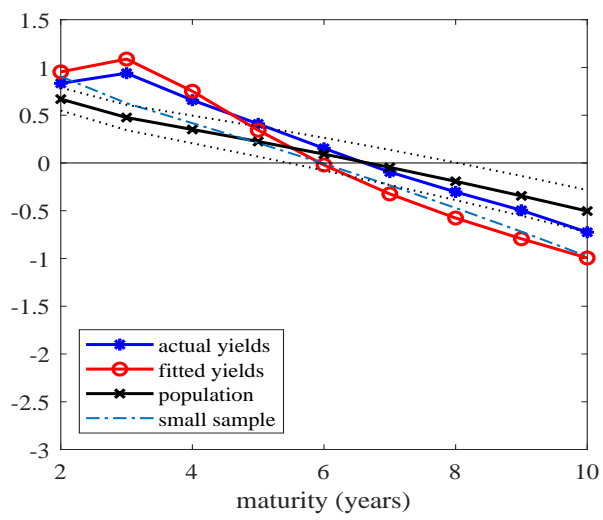

Panel D: Japan

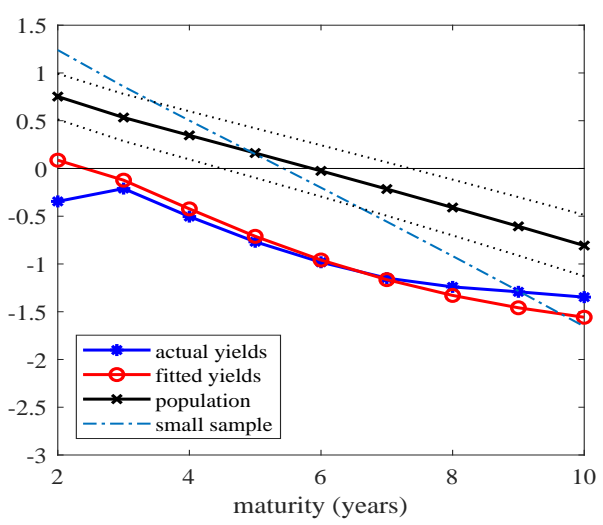




\section{Figure 2}

Components of 10-year nominal yield.

The figure displays the time series of 10-year nominal yield and its estimated components of Eq. (11) for the four markets in our study over the sample period from January 1999 (April 2004 for Japan) to December 2018.

Panel A: United States

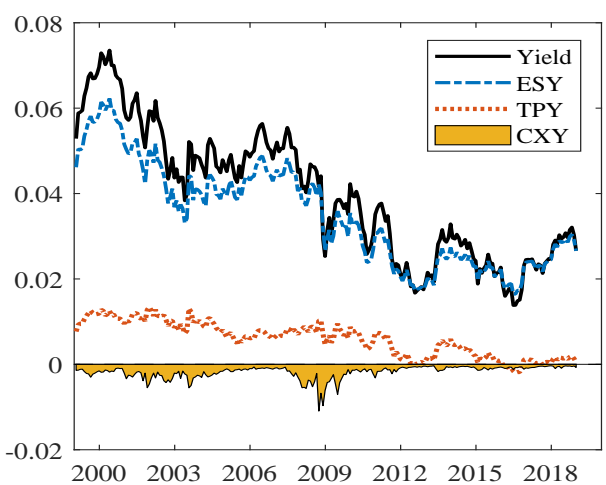

Panel C: United Kingdom

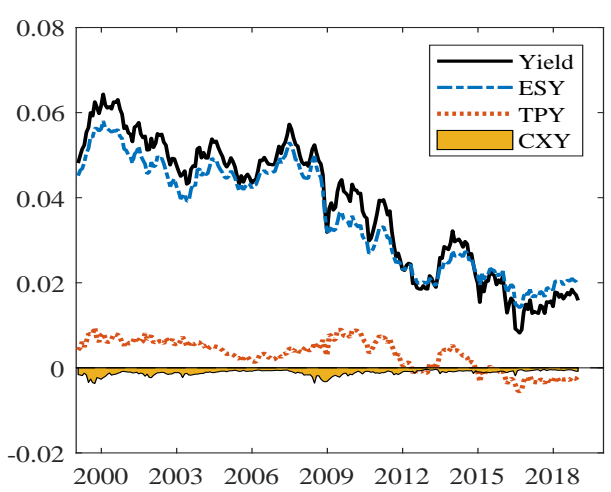

Panel B: Euro Area

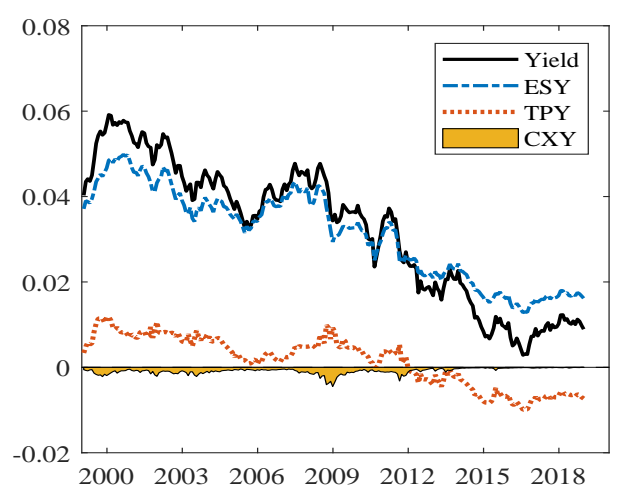

Panel D: Japan

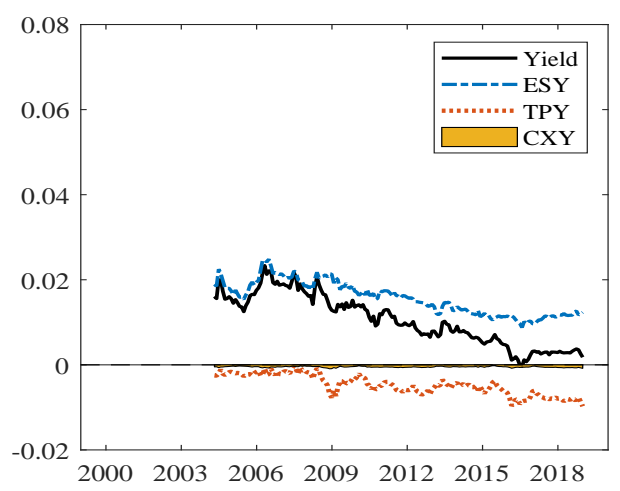




\section{Figure 3}

Inflation and real components.

The figure displays the time series of the components of the 10-year breakeven and real rate for the four markets in our study over the sample period from January 1999 (April 2004 for Japan) to December 2018. Panel A and C report the time series of the 10-year inflation short-rate expectations and inflation term premia, respectively. Panel B and panel D report the time series of the 10-year real short-rate expectations and real term premia, respectively.

Panel A: Inflation rate expectations, ESH

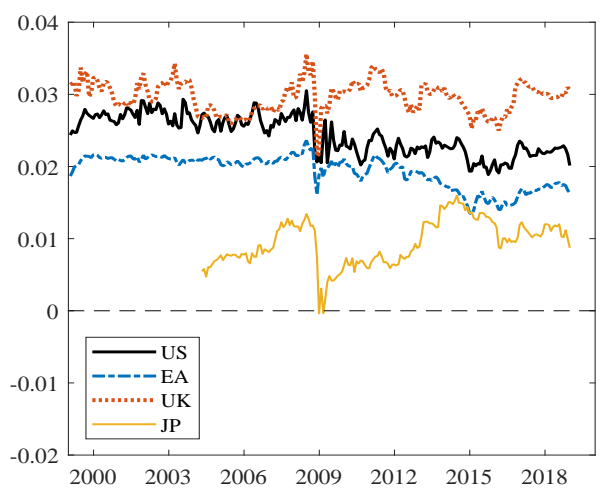

Panel C: Inflation term premium, TPH

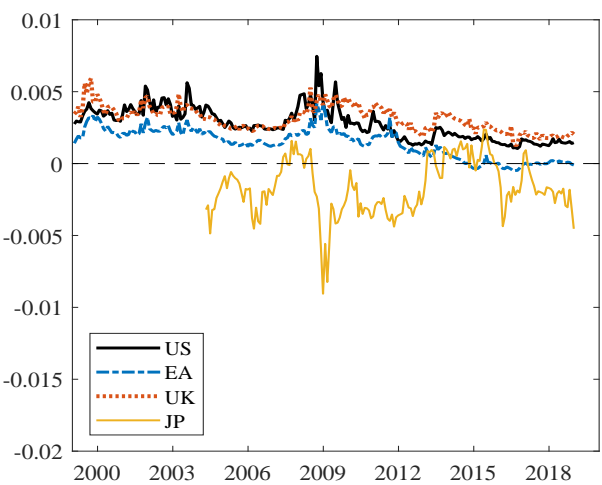

Panel B: Real rate expectations, ESR

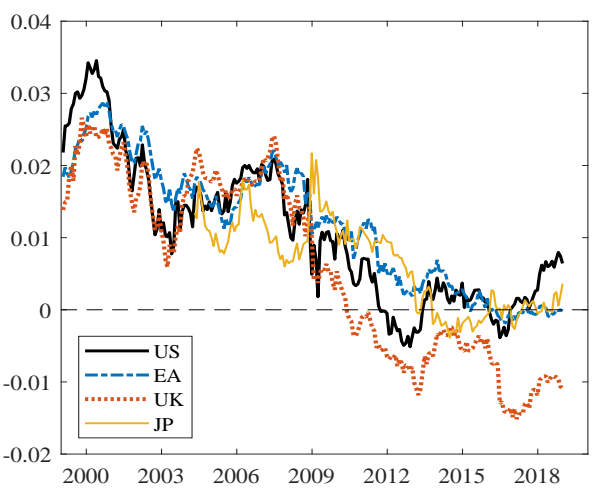

Panel D: Real term premium, TPR

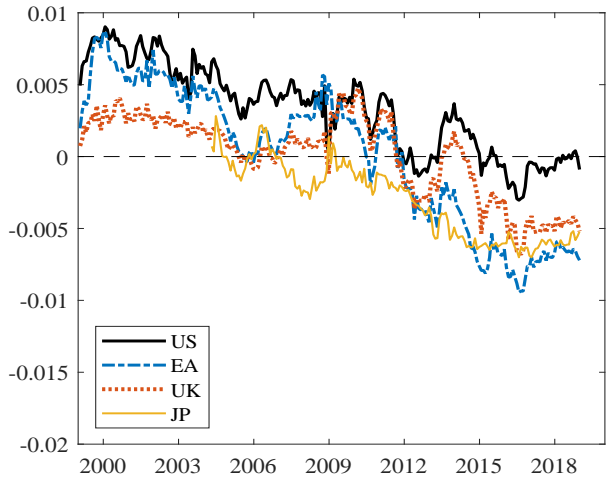




\section{Figure 4}

Term premium from alternative models.

The figure displays the US 10-year nominal term premium estimated from different models for the sample period January 1999 to December 2018. Panel A shows the time series of the term premium obtained from: (i) a five-factor Adrian et al. (2013) model, ACM; (ii) a Gaussian four-factor model with macro factors but without stochastic volatility, GM4; (iii) a stochastic volatility four-factor model without macro factor $\mu, \mathrm{SV} 4$; and (iv) our model featuring both macro factors and stochastic volatility, MSV. Panel B compares the US 10-year nominal term premium from our model with that from a four-factor nonlinear version of the Feldhütter et al. (2018) model.

Panel A: Comparison with affine models

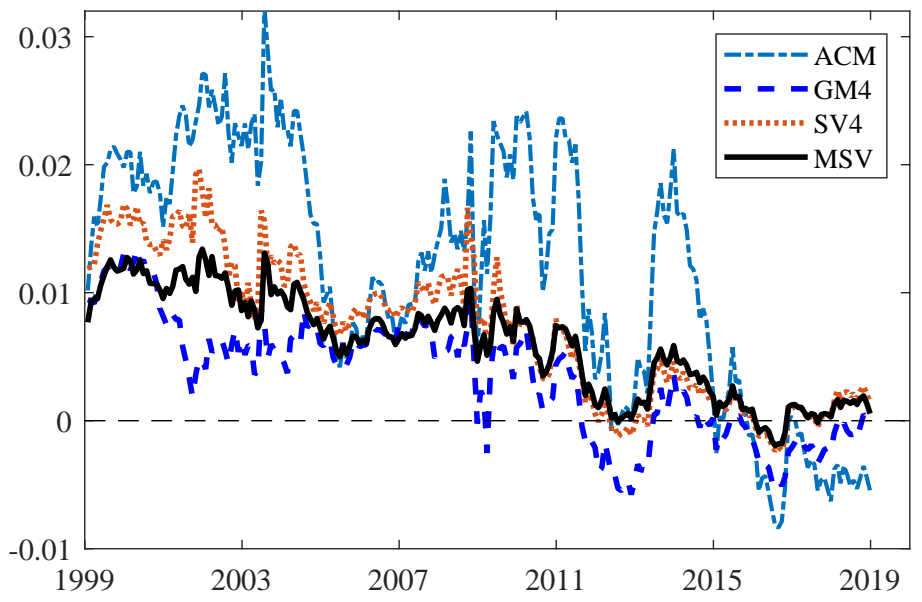

Panel B: Comparison with non-linear model

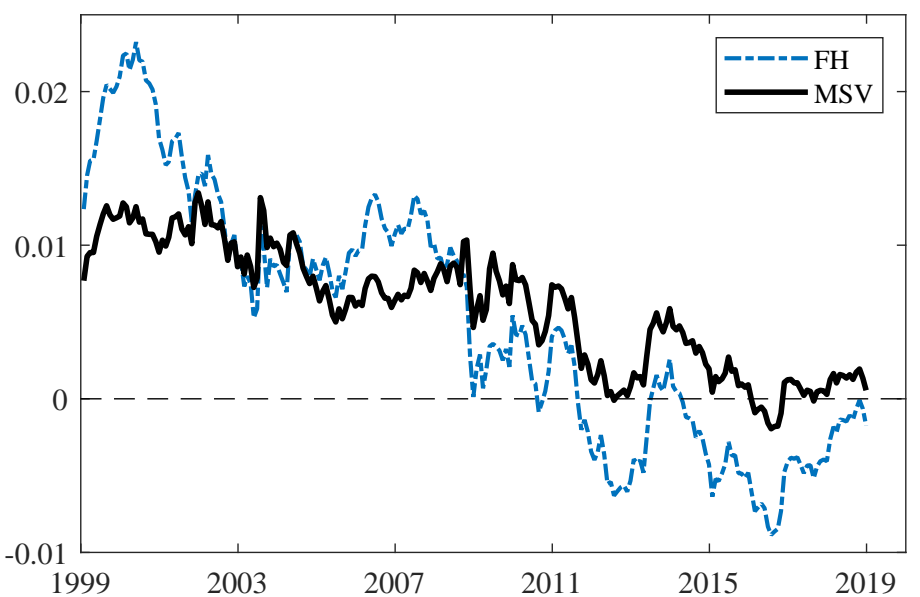




\section{Figure 5}

Equilibrium real rate.

The figure displays the time series of the model-implied long-run equilibrium real rate for the four markets in our study, computed as the average expected short rate over a five-year period starting five years ahead, over the sample period from January 1999 (April 2004 for Japan) to December 2018. For the US (Panel A), we also display the forward rate from the Gurkaynak et al. (2008) TIPS yield curve. For the UK (Panel C), we also display the forward rate from the UK Index-Linked Gilts yield curve published by the Bank of England.

Panel A: United States

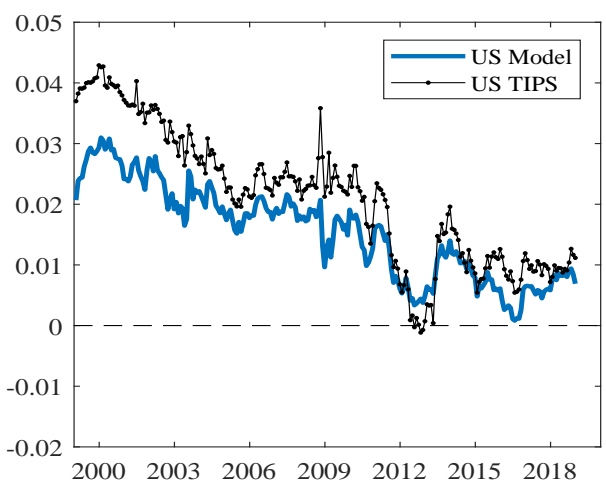

Panel C: United Kingdom

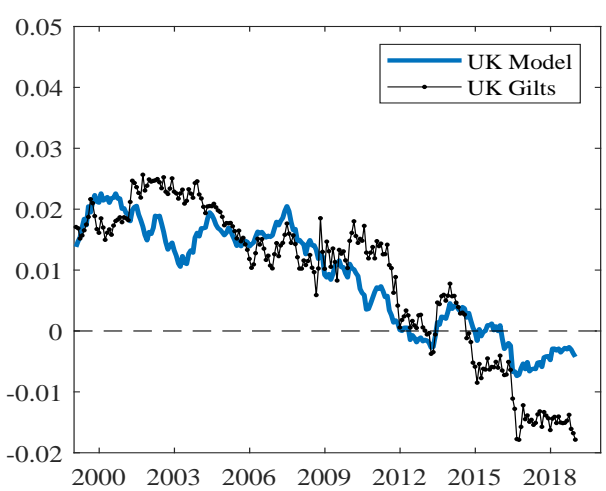

Panel B: Euro Area

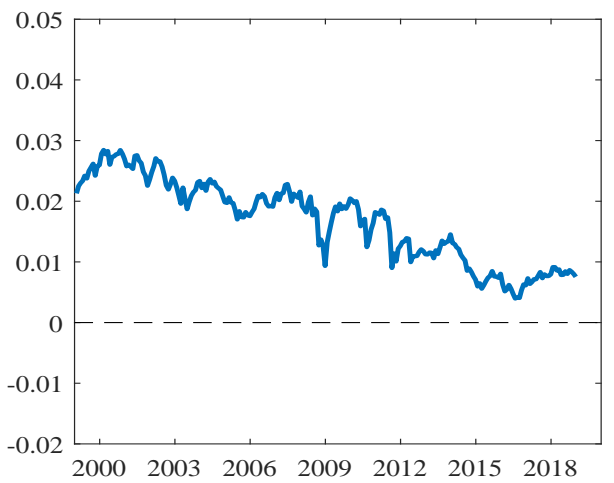

Panel D: Japan

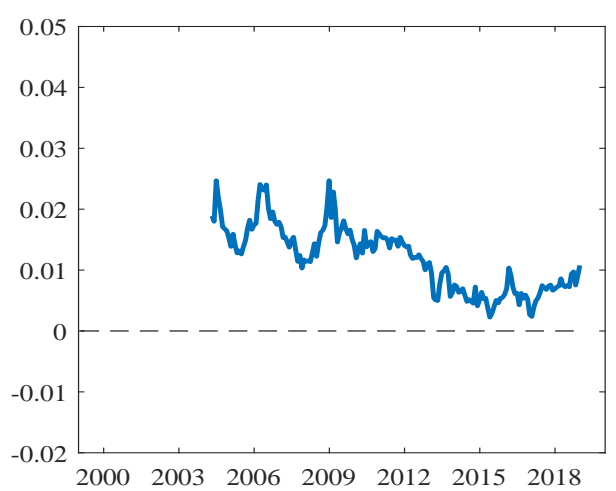




\section{Figure 6}

Model predicted vs actual correlations.

The figure displays the scatter plot of correlations in observed nominal yields $\left(\rho_{y}\right.$, Y-axis) against those in fitted nominal yields ( $\rho_{\widehat{y}}, \mathrm{X}$-axis) for the four markets in our study. Each correlation is computed between a pair of yields with the same maturity from two distinct countries, for a total of 54 observations (9 maturities, 6 combinations). In Panel A, the fitted correlations are based on the estimates from the full model of Section 2. In Panel B and C, the fitted correlations are obtained by imposing respectively a one-factor or two-factor structure in either $v$ (left plot), $\mu$ and $\pi$ (middle plot), or $s$ and $\ell$ (right plot). In the plots, we report the estimates from a linear fit, with standard errors in parentheses.

Panel A: Full model

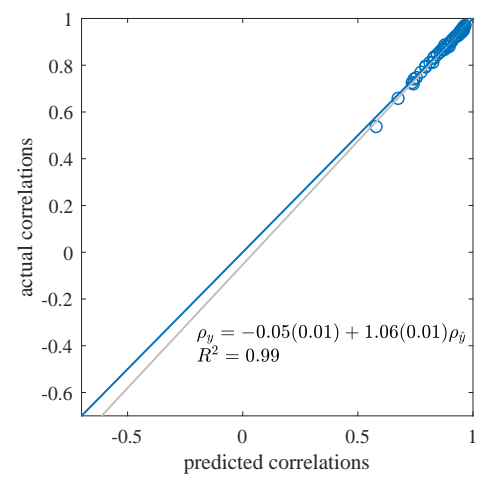

Panel B: Constrained 1-factor model
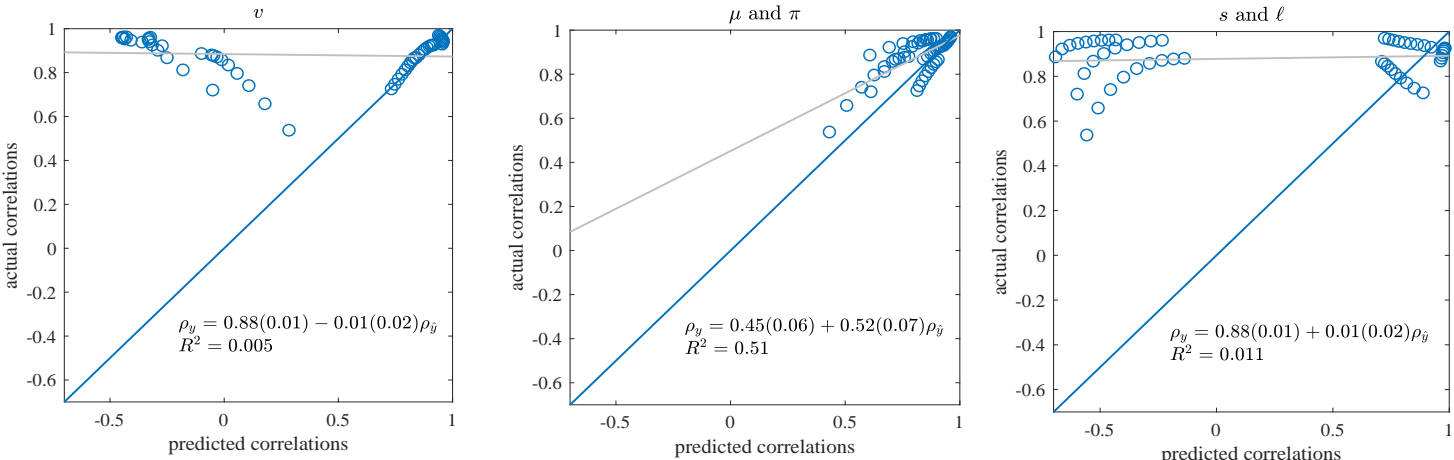

Panel C: Constrained 2-factor model
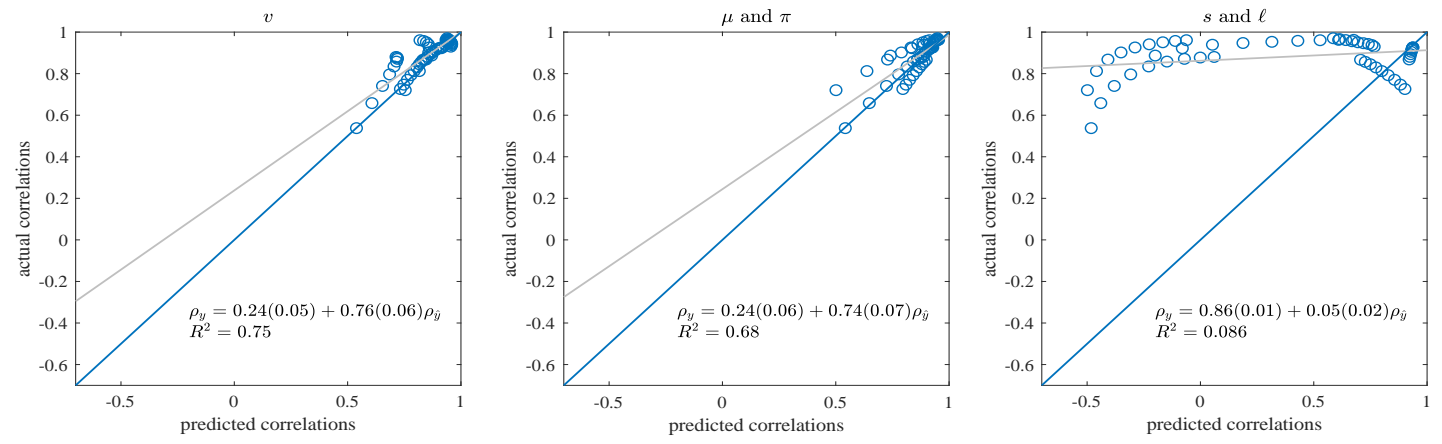


\section{Figure B.1}

Liquidity premium in breakeven rates.

The figure displays the time series of the average (across maturities) liquidity premium, as defined in equation B.2, for the four markets in our study over the sample period from July 2004 (March 2007 for Japan) to December 2018.

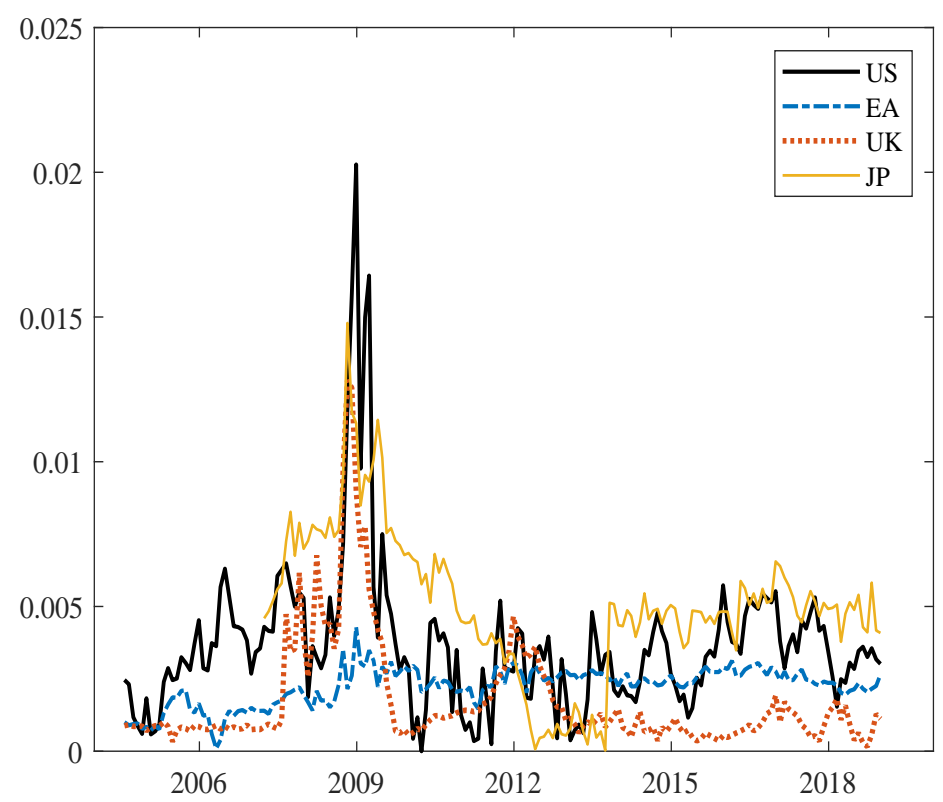




\section{Figure D.1}

Comparison with Markov-switching model.

The figure displays the time series of the square root of our estimated variance factor $\sqrt{v_{t}}$ along with the yield conditional standard deviation from estimating either a constant probability two-state Markov-switching model (top panel), or a timevarying parameter two-state Markov-switching model (bottom panel) where the conditioning set consists of a lag, the implied 10-year T-note variance and 1-year GDP survey expectations. Estimates are for the US over the sample period from January 1999 to December 2018.
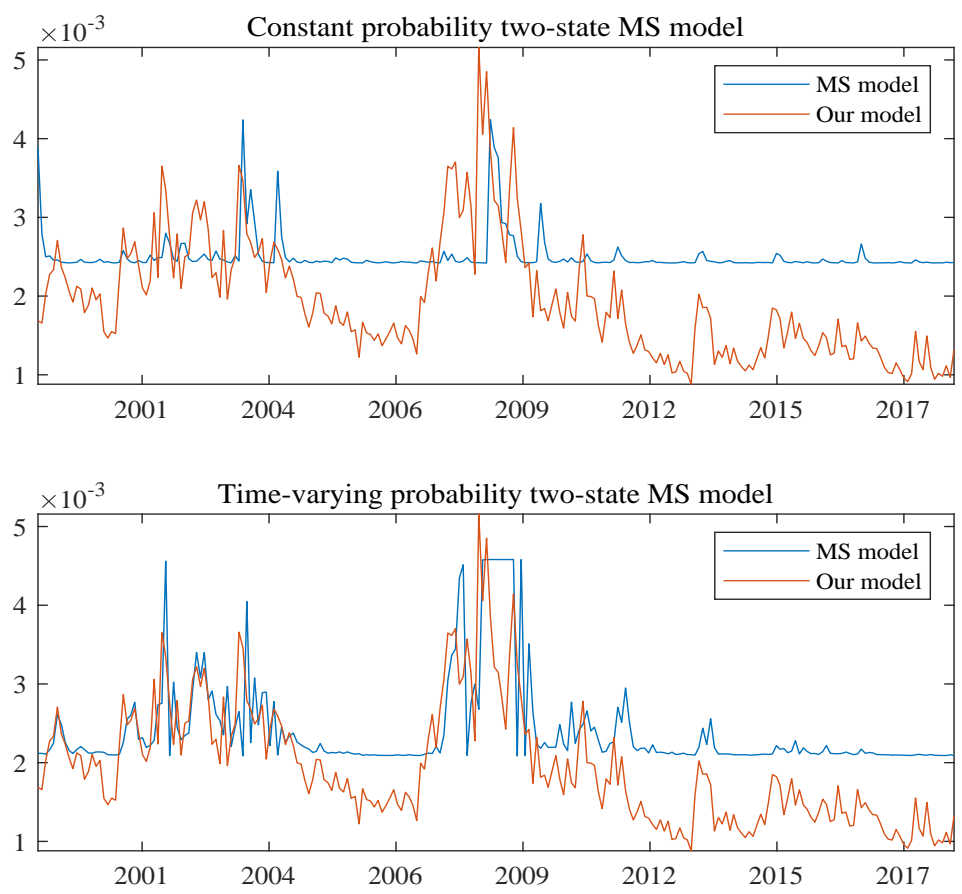
Table F.1

Parameter estimates.

\begin{tabular}{|c|c|c|c|c|c|c|c|c|c|c|c|c|c|c|c|c|c|}
\hline \multirow{2}{*}{$\begin{array}{c}\text { Parameter } \\
\kappa_{11}\end{array}$} & \multicolumn{2}{|l|}{ US } & \multicolumn{2}{|c|}{ Euro Area } & \multicolumn{2}{|l|}{ UK } & \multicolumn{2}{|c|}{ Japan } & \multirow{2}{*}{$\frac{\text { Parameter }}{\lambda_{01}}$} & \multicolumn{2}{|l|}{ US } & \multicolumn{2}{|c|}{ Euro Area } & \multicolumn{2}{|l|}{ UK } & \multicolumn{2}{|c|}{ Japan } \\
\hline & 0.3571 & $* *$ & 0.2278 & $* *$ & 0.5531 & $* *$ & 0.2215 & $* *$ & & 0.0006 & $*$ & 0.0002 & $*$ & 0.0005 & $*$ & -0.0031 & $*$ \\
\hline$\kappa_{22}$ & 0.4189 & $* *$ & 0.4182 & $* *$ & 0.4332 & $* *$ & 0.4237 & $* *$ & $\lambda_{02}$ & 0.0076 & $*$ & 0.0075 & $*$ & 0.0079 & $*$ & -0.0045 & $* *$ \\
\hline$\kappa_{33}$ & 0.3982 & $* *$ & 0.5411 & $* *$ & 0.3197 & $* *$ & 0.2296 & $* *$ & $\lambda_{03}$ & -0.0055 & $* *$ & -0.0030 & $* *$ & -0.0022 & $*$ & 0.0065 & * \\
\hline$\kappa_{44}$ & 0.3260 & $* *$ & 0.3105 & $* *$ & 0.1473 & $* *$ & 0.2493 & $* *$ & $\lambda_{04}$ & -0.0041 & $*$ & -0.0038 & $*$ & -0.0036 & $* *$ & 0.0040 & * \\
\hline$\kappa_{55}$ & 0.0661 & $* *$ & 0.0765 & $* *$ & 0.0906 & $* *$ & 0.1137 & $* *$ & $\lambda_{05}$ & -0.0005 & $* *$ & 0.0019 & $*$ & -0.0045 & $*$ & -0.0044 & * \\
\hline$\kappa_{12}$ & 0 & & 0 & & 0 & & 0 & & $\lambda_{11}$ & -5.0765 & $* *$ & -5.2955 & $* *$ & -7.1053 & $* *$ & -3.2815 & $* *$ \\
\hline$\kappa_{13}$ & 0 & & 0 & & 0 & & 0 & & $\lambda_{22}$ & -5.5034 & $* *$ & -4.5820 & $* *$ & -6.4352 & $* *$ & -2.9373 & $* *$ \\
\hline$\kappa_{14}$ & 0 & & 0 & & 0 & & 0 & & $\lambda_{33}$ & -1.1238 & $* *$ & -3.5162 & $* *$ & -2.0828 & $* *$ & -9.7179 & $* *$ \\
\hline$\kappa_{15}$ & 0 & & 0 & & 0 & & 0 & & $\lambda_{44}$ & -3.5574 & $* *$ & -4.6834 & $*$ & -4.3303 & $* *$ & -3.5908 & $* *$ \\
\hline$\kappa_{21}$ & -0.0061 & $* *$ & -0.0062 & $* *$ & -0.0035 & $* *$ & 0.0020 & $*$ & $\lambda_{55}$ & -7.2705 & $* *$ & -10.7201 & $* *$ & -13.3681 & $* *$ & -5.4298 & $* *$ \\
\hline$\kappa_{23}$ & 0.0013 & $*$ & 0.0003 & $*$ & 0.0019 & $* *$ & -0.0194 & $*$ & $\lambda_{12}$ & -0.0002 & $* *$ & 0.0000 & $*$ & -0.0001 & $* *$ & -0.0029 & $*$ \\
\hline$\kappa_{24}$ & -0.0005 & $*$ & -0.0009 & $* *$ & -0.0003 & $* *$ & 0.0053 & $*$ & $\lambda_{13}$ & 0.0017 & $*$ & 0.0022 & $*$ & 0.0012 & $* *$ & 0.0005 & $* *$ \\
\hline$\kappa_{25}$ & -0.0131 & $*$ & -0.0139 & $* *$ & -0.0138 & $* *$ & -0.0012 & $* *$ & $\lambda_{14}$ & 0.0034 & $* *$ & 0.0039 & $*$ & 0.0017 & $* *$ & -0.0063 & * \\
\hline$\kappa_{31}$ & -0.0030 & $*$ & -0.0077 & $* *$ & -0.0085 & $* *$ & 0.0405 & $* *$ & $\lambda_{15}$ & 0.0030 & $* *$ & 0.0006 & $* *$ & 0.0031 & $* *$ & 0.0001 & $* *$ \\
\hline$\kappa_{32}$ & -0.0106 & $*$ & -0.0049 & $* *$ & -0.0061 & $* *$ & -0.0052 & $*$ & $\lambda_{21}$ & 0.0057 & $* *$ & 0.0043 & $* *$ & 0.0067 & $* *$ & 0.0029 & $*$ \\
\hline$\kappa_{34}$ & 0.0208 & $* *$ & 0.0123 & $* *$ & 0.0171 & $*$ & -0.0138 & $*$ & $\lambda_{23}$ & 0.0080 & $*$ & 0.0067 & $* *$ & 0.0037 & $*$ & -0.0004 & $* *$ \\
\hline$\kappa_{35}$ & -0.1038 & $*$ & -0.0845 & $* *$ & -0.1068 & $* *$ & -0.0070 & $*$ & $\lambda_{24}$ & 0.0087 & & 0.0118 & $*$ & 0.0037 & $* *$ & 0.0010 & $* *$ \\
\hline$\kappa_{41}$ & 0.0045 & $*$ & -0.0159 & $* *$ & 0.0002 & $* *$ & 0.0235 & $*$ & $\lambda_{25}$ & 0.0111 & $*$ & 0.0142 & $* *$ & 0.0067 & $* *$ & 0.0012 & $* *$ \\
\hline$\kappa_{42}$ & 0.0046 & $* *$ & 0.0041 & $* *$ & 0.0028 & $* *$ & 0.0264 & $*$ & $\lambda_{31}$ & 0.0030 & $*$ & 0.0033 & $* *$ & 0.0145 & $*$ & -0.0002 & $* *$ \\
\hline$\kappa_{43}$ & -0.0192 & $*$ & -0.0141 & $*$ & -0.0195 & $* *$ & 0.0095 & $*$ & $\lambda_{32}$ & 0.0045 & $*$ & 0.0054 & $* *$ & 0.0039 & $* *$ & -0.0127 & $* *$ \\
\hline$\kappa_{45}$ & -0.0775 & $* *$ & -0.0790 & $* *$ & -0.1105 & $* *$ & -0.0066 & $*$ & $\lambda_{34}$ & 0.0071 & $*$ & 0.0036 & $* *$ & 0.0060 & $*$ & 0.0033 & $* *$ \\
\hline$\kappa_{51}$ & -0.0025 & $* *$ & -0.0012 & $* *$ & 0.0010 & $*$ & 0.0162 & $* *$ & $\lambda_{35}$ & 0.0016 & $* *$ & 0.0010 & $* *$ & 0.0023 & $* *$ & 0.0001 & $* *$ \\
\hline$\kappa_{52}$ & 0.0260 & $* *$ & 0.0328 & $* *$ & 0.0264 & $* *$ & 0.0027 & $* *$ & $\lambda_{41}$ & 0.0083 & $* *$ & 0.0107 & $* *$ & 0.0099 & $*$ & 0.0005 & $* *$ \\
\hline$\kappa_{53}$ & -0.0323 & $* *$ & -0.0361 & $* *$ & -0.0198 & $* *$ & -0.0030 & $* *$ & $\lambda_{42}$ & 0.0067 & $* *$ & 0.0062 & $* *$ & 0.0051 & $* *$ & -0.0029 & $*$ \\
\hline$\kappa_{54}$ & 0.0024 & $*$ & 0.0024 & $* *$ & 0.0006 & $* *$ & 0.0002 & $* *$ & $\lambda_{43}$ & 0.0025 & $*$ & 0.0019 & $* *$ & 0.0032 & $* *$ & 0.0070 & * \\
\hline$\theta_{1}$ & 0.0329 & $*$ & 0.0346 & $* *$ & 0.0435 & $*$ & 0.0021 & $* *$ & $\lambda_{45}$ & 0.0044 & $* *$ & 0.0063 & $*$ & 0.0041 & $* *$ & 0.0005 & $*$ \\
\hline$\theta_{2}$ & 0.0408 & $* *$ & 0.0231 & $* *$ & 0.0418 & $* *$ & 0.0246 & $* *$ & $\lambda_{51}$ & 0.0100 & $*$ & 0.0119 & $* *$ & 0.0102 & $* *$ & -0.0003 & $* *$ \\
\hline$\theta_{3}$ & 0.0207 & $* *$ & 0.0204 & $* *$ & 0.0291 & $* *$ & 0.0159 & $* *$ & $\lambda_{52}$ & 0.0035 & $*$ & 0.0034 & $* *$ & 0.0032 & $* *$ & 0.0003 & $* *$ \\
\hline$\theta_{4}$ & 0.0020 & $* *$ & 0.0223 & $* *$ & 0.0059 & $* *$ & 0.0070 & $* *$ & $\lambda_{53}$ & 0.0059 & $*$ & 0.0071 & $* *$ & 0.0092 & $*$ & 0.0006 & $* *$ \\
\hline$\theta_{5}$ & 0.0121 & $* *$ & 0.0231 & $* *$ & 0.0178 & $* *$ & 0.0185 & $* *$ & $\lambda_{54}$ & 0.0030 & $*$ & 0.0027 & $*$ & 0.0031 & $*$ & 0.0002 & $* *$ \\
\hline$\sigma_{1}$ & 0.0573 & $* *$ & 0.0362 & $* *$ & 0.0356 & $* *$ & 0.0666 & $* *$ & & & & & & & & & \\
\hline$\sigma_{2}$ & 0.0152 & $* *$ & 0.0097 & $* *$ & 0.0128 & $* *$ & 0.0187 & $* *$ & & & & & & & & & \\
\hline$\sigma_{3}$ & 0.0090 & $* *$ & 0.0082 & $* *$ & 0.0049 & $* *$ & 0.0105 & $* *$ & & & & & & & & & \\
\hline$\sigma_{4}$ & 0.0059 & $* *$ & 0.0096 & $* *$ & 0.0071 & $* *$ & 0.0152 & $* *$ & & & & & & & & & \\
\hline$\sigma_{5}$ & 0.0098 & $* *$ & 0.0082 & $* *$ & 0.0073 & $* *$ & 0.0127 & $* *$ & & & & & & & & & \\
\hline$\sigma_{p}$ & 0.0511 & $* *$ & 0.0597 & $* *$ & 0.0534 & $* *$ & 0.0073 & $* *$ & & & & & & & & & \\
\hline$\sigma_{q}$ & 0.0536 & $* *$ & 0.0441 & $* *$ & 0.0422 & $* *$ & 0.0157 & $* *$ & & & & & & & & & \\
\hline$\rho_{p 1}$ & 0.0156 & $*$ & 0.0111 & $*$ & 0.0270 & $*$ & 0.0000 & & & & & & & & & & \\
\hline$\rho_{p 2}$ & 0.0143 & $*$ & 0.0177 & $*$ & 0.0071 & $*$ & 0.0000 & & & & & & & & & & \\
\hline$\rho_{p 3}$ & 0.6390 & $*$ & 0.7043 & $*$ & 0.6866 & $*$ & 0.7365 & & & & & & & & & & \\
\hline$\rho_{p 4}$ & 0.0042 & $*$ & 0.0048 & $*$ & 0.0038 & $*$ & 0.0000 & & & & & & & & & & \\
\hline$\rho_{p 5}$ & 0.0227 & $*$ & 0.0244 & $*$ & 0.0297 & & 0.0000 & & & & & & & & & & \\
\hline$\rho_{12}$ & 0.1178 & & 0.0984 & & 0.1716 & $*$ & -0.0112 & $*$ & & & & & & & & & \\
\hline$\rho_{13}$ & -0.0232 & & -0.0119 & $*$ & -0.0089 & $*$ & 0.0083 & $*$ & & & & & & & & & \\
\hline$\rho_{14}$ & 0.1344 & $*$ & 0.0692 & $*$ & 0.1017 & $*$ & 0.0036 & $*$ & & & & & & & & & \\
\hline$\rho_{15}$ & -0.0225 & $*$ & -0.0295 & $* *$ & -0.0235 & $*$ & 0.0000 & & & & & & & & & & \\
\hline$\rho_{23}$ & 0.0209 & $*$ & 0.0287 & $*$ & 0.0225 & & 0.0039 & & & & & & & & & & \\
\hline$\rho_{24}$ & -0.6862 & $* *$ & 0.0001 & & -0.6696 & $* *$ & 0.0229 & & & & & & & & & & \\
\hline$\rho_{25}$ & 0.0205 & & 0.0288 & $*$ & 0.0310 & & 0.0000 & & & & & & & & & & \\
\hline$\rho_{34}$ & -0.4928 & $* *$ & -0.5246 & $*$ & -0.2692 & $*$ & -0.0504 & & & & & & & & & & \\
\hline$\rho_{35}$ & 0.0113 & $*$ & 0.0096 & & 0.0107 & & 0.0000 & & & & & & & & & & \\
\hline$\rho_{45}$ & 0.0196 & & 0.0216 & & 0.0118 & $*$ & 0.0000 & & & & & & & & & & \\
\hline
\end{tabular}

The table reports maximum likelihood estimates of the model parameters. The coefficients are ordered as $[v ; \mu ; \pi ; s ; \ell]$. indicates statistical significance at $5 \%$ level and * at $10 \%$ level based on bootstrapped standard errors. 


\section{Table F.2}

Goodness of fit.

\begin{tabular}{lrrrr}
\hline Panel A: Fitting errors & & & & \\
\hline & & & & \\
Variable & 7.8 & 6.2 & 8.3 & 2.7 \\
\hline Nominal Yields & 15.0 & 9.5 & 13.2 & 11.5 \\
Breakeven Rates & 17.5 & 15.0 & 16.6 \\
Realized Yield Volatilities & 17.5 & 10.8 & 10.8 & 16.6 \\
Implied Yield Volatilities & 12.7 & 24.2 & 38.8 & 31.9 \\
Inflation Rate Forecast & 42.9 & 3.7 & 4.3 & 1.6 \\
Real GDP Growth Forecast & 3.5 & & & \\
& & & & \\
Panel B: Maximal Sharpe Ratio & & & \\
\hline
\end{tabular}

\begin{tabular}{lrrrr} 
Statistic & US & Euro Area & UK & Japan \\
\hline Mean & 0.99 & 0.89 & 1.26 & 0.30 \\
Standard Deviation & 0.38 & 0.31 & 0.32 & 0.05 \\
Maximum & 2.62 & 2.20 & 2.33 & 0.48 \\
\hline
\end{tabular}

The table reports summary statistics for fitting errors. Panel A contains the average (across maturities) of the standard deviation of fitting errors for: nominal yields and breakeven rates with maturity ranging between 2 and 10 years; realized and implied yield volatilities with maturity 2, 5 and 10 years; and survey forecasts of the 1-year-ahead inflation rate and GDP growth rate. Values are expressed in basis points. Panel B reports mean, standard deviation and maximum value of the estimated maximal Sharpe Ratio. 


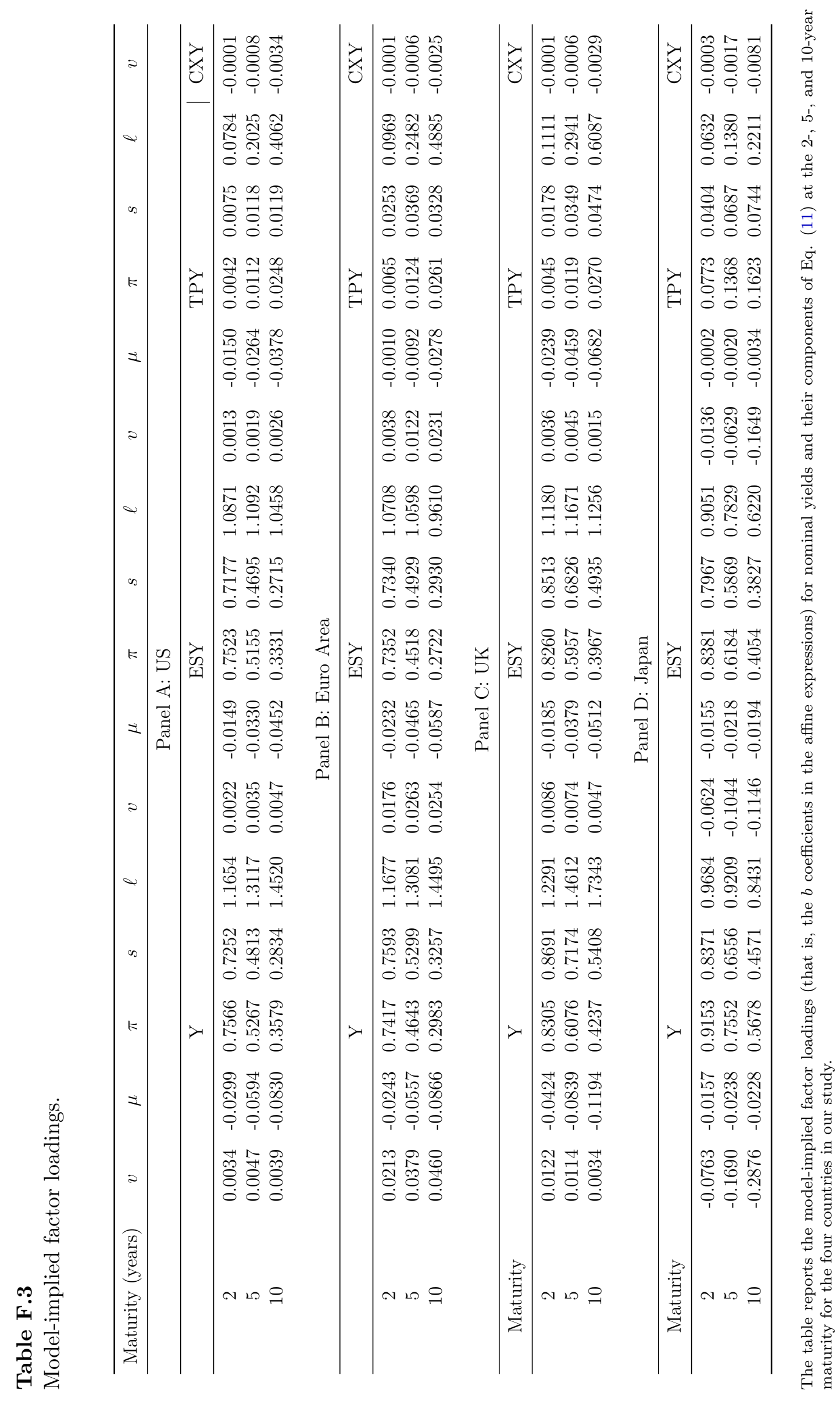




\section{Table F.4}

Yield components estimated using Treasury bond yields.

\begin{tabular}{lccc}
\hline Component & Corr. Level & Corr. Changes & Var. Dec. \\
\hline \multicolumn{4}{c}{ US } \\
& 1 & 0.98 & 73.02 \\
\hline Expected short rate & 0.98 & 0.95 & 26.98 \\
Term premium & 0.99 & 0.95 & 0.00 \\
Convexity & \multicolumn{4}{c}{} \\
& France/Euro Area & \\
& 0.99 & 0.83 & 70.32 \\
Expected short rate & 0.96 & 0.83 & 29.67 \\
Term premium & 0.94 & 0.76 & 0.01 \\
Convexity & \multicolumn{4}{c}{} \\
& UK & & \\
& 0.98 & 0.82 & 72.77 \\
Expected short rate & 0.88 & 0.71 & 27.22 \\
Term premium & 0.95 & 0.81 & 0.01 \\
Convexity & &
\end{tabular}

The table reports the results from fitting the model on Treasury bond data for the sample period January 1999 to December 2018. The first two columns of the table report the correlations in level and in first difference of each of the resulting yield components (at the 10-year maturity) with those estimated using swap rates. The last column reports the model-implied decomposition of the 1-month-ahead forecast error variance of the 10-year nominal yield. 